Research Article

\title{
VEGF Contributes to Mesenchymal Stem Cell-Mediated Reversion of Nor1-Dependent Hypertrophy in iPS Cell- Derived Cardiomyocytes
}

\author{
Denise Philipp, ${ }^{1}$ Michelle Holthaus, ${ }^{1}$ Vida Basoah, ${ }^{1}$ Kurt Pfannkuche, ${ }^{2}$ Laura Suhr, ${ }^{1}$ \\ Thorsten Wahlers, ${ }^{1}$ and Adnana Paunel-Görgülïi ${ }^{1}{ }^{1}$ \\ ${ }^{1}$ Department of Cardiothoracic Surgery, Heart Center of the University of Cologne, Cologne, Germany \\ ${ }^{2}$ Center for Physiology and Pathophysiology, Institute for Neurophysiology, University of Cologne, Medical Faculty, \\ Cologne, Germany \\ Correspondence should be addressed to Adnana Paunel-Görgülü; adnana.paunel-goerguelue@uk-koeln.de
}

Received 10 August 2020; Revised 2 March 2021; Accepted 24 March 2021; Published 10 April 2021

Academic Editor: Kenichi Tamama

Copyright (C) 2021 Denise Philipp et al. This is an open access article distributed under the Creative Commons Attribution License, which permits unrestricted use, distribution, and reproduction in any medium, provided the original work is properly cited.

\begin{abstract}
Myocardial hypertrophy is present in many heart diseases, representing a strong predictor of adverse cardiovascular outcomes. Regarding therapeutic intervention, mesenchymal stem cells (MSCs) have been suggested to significantly reduce cardiac hypertrophy and progression to heart failure. Preconditioning of MSCs was previously demonstrated to highly improve their paracrine activity resulting in modulation of immune responses and the progression of diseases. Here, we studied the effects of bone marrow-derived preconditioned MSCs on hypertrophied induced pluripotent stem cell-derived cardiomyocytes (iPS-CM) and also sought to identify MSC-derived antihypertrophic molecules. Phenylephrine (PE) was used to induce hypertrophy in murine iPS-CM, and markers of hypertrophy were identified by microarray analysis. Murine MSCs were treated with IFN- $\gamma$ and IL- $1 \beta$ to enhance their paracrine activity, and transcriptional profiling was performed by microarray analysis. Hypertrophied iPS-CM were subsequently cocultured with preconditioned MSCs or MSC-conditioned medium (CM), respectively. Effects on hypertrophied iPS-CM were studied by cell area quantification, real-time PCR, and western blot. In some experiments, cells were incubated with fractions of MSC-CM obtained by ultrafiltration or by MSC-CM supplemented with inhibitory antibodies. Intracellular and extracellular levels of vascular endothelial growth factor (VEGF) were evaluated by western blot and ELISA. PE-induced hypertrophy in iPS-CM was associated with an upregulation of neuron-derived orphan receptor (Nor1) expression, activation of Akt, and inhibition of both strongly prevented hypertrophy induction in iPS-CM. VEGF secreted by preconditioned MSCs provoked hypertrophy regression in iPS-CM, and a negative correlation between Nor1 expression and hypertrophic growth could be evidenced. Our results demonstrate that Nor1 expression strongly supports hypertrophy in iPSCM. Moreover, the secretome of preconditioned MSCs triggered regression of hypertrophy in iPS-CM in a VEGF-dependent manner. We suggest that the delivery of the MSC-derived secretome may represent a therapeutic strategy to limit cardiac hypertrophy. However, additional in vivo studies are needed to prove this hypothesis.
\end{abstract}

\section{Introduction}

Left ventricular hypertrophy (LVH) is a common manifestation of many forms of cardiac disease, including myocardial infarction and hypertension [1]. It is widely recognized as a major risk factor for the development of heart failure and cardiac sudden death representing an established predictor of cardiovascular morbidity and mortality. LVH is a complex and multifactorial condition involving a process of adaptive remodeling, which is usually a compensatory mechanism in response to increased hemodynamic load [2]. Although called compensatory, prolonged hypertrophy increases the risk for progression into heart failure (decompensated hypertrophy). LVH is accompanied by various cardiac and molecular changes, including increase in protein synthesis, cell sizes, and inflammatory and fibrogenic responses which lead 
to myocardial remodeling and subsequent ventricular dysfunction [1]. Inflammation was shown to be a prominent hallmark of LVH in animal [3] and human studies [4]. Increased wall stress associated with LV overload promotes remodeling processes characterized by increased proinflammatory cytokine expression, leukocyte infiltration, and myocardial destruction. Since a variety of signaling pathways have been shown to be involved in the progression of cardiac hypertrophy [5], understanding the mechanisms underlying the development of cardiac hypertrophy is essential for the treatment of cardiovascular disease. Accordingly, reversal of myocardial hypertrophy has been considered a therapeutic strategy for the reduction of adverse remodeling and prevention of heart failure [6].

The NR4A orphan nuclear receptor subfamily consists of the highly homologous receptors Nur77 (NR4A1), Nurr1 (NR4A2), and Nor1 (NR4A3) which can be regulated by various stimuli, including growth factors, hormones, and inflammatory signals. Recently, there has been much attention paid to the function of these receptors in the cardiovascular system [7]. Nor1 was shown to regulate a number of essential biological processes including inflammation [8], and the first evidence has already been provided for its prohypertrophic properties $[9,10]$. Therapeutic strategies targeting hypertrophic markers to dampen the inflammatory response may hold promise for beneficial intervention in LVH. In this context, modulation of a macrophage phenotype has been proposed as a new therapeutic approach, as these cells are recognized as key players in cardiovascular diseases. Exacerbated local inflammation in the myocardium mediated by proinflammatory microRNA-155-expressing M1 macrophages induced cardiac hypertrophy and failure in response to pressure overload [11]. In turn, microRNA155 knockout in macrophages, but not in cardiomyocytes, markedly reduced inflammation, hypertrophy, and dysfunction in pressure overload. Recently, regression of cardiac hypertrophy by stem cell transplantation and subsequent macrophage polarization towards an anti-inflammatory M2 phenotype was demonstrated [12]. Besides, stem cell-based therapies are currently considered for the treatment of heart failure. Several studies, including clinical studies, have shown that the transplantation of mesenchymal stem cells (MSCs) may enhance tissue perfusion and angiogenesis and preserve or regenerate the myocardial tissue [13-16]. In this context, the prior research of our group has demonstrated that transfer of bone marrow-derived MSCs to the myocardium improves global function and remodeling in mice [17]. MSCs are able to secrete cytokines, growth factors, microRNAs, and exosomes which are potent for improving neovascular formation, attenuating inflammation and adverse remodeling, and inducing endogenous cardiac regeneration. Rather, the secretome of bone marrow-derived MSCs was found to favor an immunosuppressive environment [18-20]. At present, MSCs are still the most suitable for clinical treatment [21]. Preconditioning of MSCs highly increases their efficacy in vitro and in vivo, thus preventing loss of biological function, enhancing their biological activity, and representing a more attractive strategy for clinical use [22].
In this study, we have established an in vitro model of cardiac hypertrophy on the basis of murine iPS cell-derived cardiomyocytes (iPS-CM) and studied the hypertrophic response. We further investigated whether preconditioned MSCs might reverse hypertrophy in iPS-CM and identified VEGF as a major contributor of MSC-mediated hypertrophy regression.

\section{Materials and Methods}

2.1. Cell Culture Conditions for Murine iPS-CM and Hypertrophy Induction. Differentiated, nonproliferative murine iPS-CM were kindly provided by Dr. Kurt Pfannkuche (Institute of Neurophysiology, University of Cologne). These cells exhibit spontaneous contraction and unimpaired physiological function as evidenced by action potential generation, functional hormonal regulation, and sensitivity to ion channel blockers [23]. Cells were seeded on fibronectincoated culture dishes $\left(2.6 \mu \mathrm{g} / \mathrm{cm}^{2}\right)$ and cultured in IMDM medium with GlutaMAX (Gibco), 20\% FCS (PAN), 1\% nonessential amino acids (Gibco), 0.1 mM 2-mercaptoethanol (Gibco), and $100 \mathrm{U} / \mathrm{ml}$ penicillin/streptomycin (SigmaAldrich). The medium was renewed every day. To induce hypertrophy, cells were starved in IMDM medium with GlutaMAX supplemented with 1\% FCS for $24 \mathrm{~h}$ and further treated with L-phenylephrine (PE, $100 \mu \mathrm{M}$, Sigma-Aldrich) for additional $24 \mathrm{~h}$. In some experiments, hypertrophied iPS-CM were cultured in medium supplemented with MSC-conditioned medium (CM) or fractions from MSC$\mathrm{CM}$ and $\mathrm{PE}(100 \mu \mathrm{M})$ in the presence or absence of polyclonal goat anti-mouse VEGF 164 antibodies (R\&D Systems).

2.2. Isolation, Characterization, and Activation of Bone Marrow-Derived MSCs. Isolation and characterization of mouse bone marrow-derived MSCs were previously reported by our group in detail. Cells were positive for classical MSC markers including Sca-1, CD49e, CD44, and CD29 and did not express CD45 and CD11b, respectively. The MSC phenotype was confirmed by the analysis of its differentiation potential into chondrocytes, adipocytes, and osteoblasts [20]. For experiments, MSCs were stimulated with $30 \mathrm{ng} / \mathrm{ml}$ recombinant murine IFN- $\gamma$ (PeproTech) and $3 \mathrm{ng} / \mathrm{ml}$ recombinant murine IL-1 $\beta$ (PeproTech) in MSC culture medium (Pan-Biotech) supplemented with $2.5 \mathrm{ng} / \mathrm{ml}$ human basic fibroblast growth factor FGF (FGF-b, PeproTech), $100 \mathrm{U} / \mathrm{ml}$ penicillin, and $10 \mu \mathrm{g} / \mathrm{ml}$ streptomycin (Sigma-Aldrich) for $24 \mathrm{~h}$. Preconditioned MSCs possess anti-inflammatory and immunomodulatory capacities [20] and were used for coculture experiments.

To gain MSC-CM, preconditioned MSCs were further cultured in serum-free IMDM medium with stable glutamine (Gibco) for additional $24 \mathrm{~h}$. Then, supernatants were collected and stored at $-80^{\circ} \mathrm{C}$ until further processing. To prove if MSCs retain their immunomodulatory properties upon serum starvation, nitrite levels in culture supernatants were quantified using a modified Griess reagent (Sigma-Aldrich) as already described [20]. Supernatants containing high levels of nitrite, indicating upregulated iNOS expression, were used for experiments. 
2.3. Coculture Conditions. For coculture experiments, hypertrophied iPS-CM were indirectly cocultured with preconditioned MSCs (5:1 ratio) in IMDM medium supplemented with $1 \%$ FCS and $100 \mu \mathrm{M} \mathrm{PE}$ for $24 \mathrm{~h}$. For this, conditioned MSCs were placed in transwell inserts with $0.4 \mu \mathrm{m}$ pore size (Corning) to avoid direct cellular interactions.

2.4. Immunofluorescence Analysis. iPS-CM $\left(1.5 \times 10^{4}\right)$ were grown on fibronectin-coated coverslips in a 12-well plate, starved for $24 \mathrm{~h}$, and treated with $100 \mu \mathrm{M}$ PE in the presence of $1 \%$ FCS. Then, cells were cocultured with preconditioned MSCs or treated with MSC-CM or fractionated supernatant, respectively, in the presence of PE. After $24 \mathrm{~h}$, cells were fixed with $4 \%$ paraformaldehyde for $20 \mathrm{~min}$ and permeabilized with $0.1 \%$ Triton X-100, and nonspecific binding sites were blocked using 1\% BSA diluted in PBS. Cells were further incubated with Alexa Fluor ${ }^{\circledR} 555$ phalloidin (Thermo Scientific) in blocking solution for 20 min to stain F-actin, followed by counterstaining with DAPI. The coverslips were then washed and mounted on glass slides. Fluorescent images were obtained using a Nikon Eclipse Ti-U inverted microscope (Eclipse Ti-U 100, Nikon, Germany) using the software NIS-Elements version 3.00. Cell surface areas $\left(\mu \mathrm{m}^{2}\right)$ of 100 or more cells per condition were measured in 10 randomly chosen fields.

2.5. Real-Time PCR. Total RNA from iPS-CM was isolated by using the RNeasy Mini Kit (Qiagen) and reverse transcribed with High Capacity cDNA Reverse Transcription Kit (Applied Biosystems). Target genes were amplified by realtime PCR using StepOnePlus or QuantStudio 3 Real-Time PCR System (Applied Biosystems) and Power SYBR Green PCR master mix (Applied Biosystems). The following Nor1 primers were used: for: $5^{\prime}$-AGACGCCGAAACCGATGT$3^{\prime}$ and rev: $5^{\prime}$-TCGGACAAGGGCATTCA-3' . Gene expression was normalized to $18 \mathrm{~S}$ rRNA. All samples were run in triplicate. Fold expression was calculated using the $2^{-\Delta \Delta} \mathrm{C}_{\mathrm{T}}$ method.

2.6. Microarray Analysis. RNA was extracted using RNeasy Mini Kit (Qiagen), and contaminating DNA was removed by DNA-free Kit (Ambion). Gene expression profiling of hypertrophied iPS-CM and preconditioned MSCs was performed using GeneChip Mouse Genome 430.2 (Affymetrix) or Clariom S Assays (Thermo Fisher) at the Gene Expression Affymetrix Facility headed by Prof. Agapios Sachinidis (Center of Molecular Medicine, Cologne). RNA from 3-5 independent experiments was used.

2.7. siRNA Transfection. To knockdown Nor1 expression, iPS-CM were seeded in 6-well plates or alternatively on coated coverslips in 12-well plates and cultured in IMDM medium $+1 \%$ FCS. Transfection has been performed using OptiMEM medium (Gibco) and Lipofectamine RNAiMAX Reagent (Invitrogen) according to the manufacturer's instructions. Cells were transfected with $5.5 \mathrm{nM}$ Silencer Select Nor1 siRNA and Silencer Select negative control siRNA (Ambion), respectively, and incubated for $24 \mathrm{~h}$ at $37^{\circ} \mathrm{C}$ and $5 \% \mathrm{CO}_{2}$. Then, $100 \mu \mathrm{M}$ PE was added and cells were cultured for additional $24 \mathrm{~h}$. Transfection efficiency was verified by real-time PCR. Cells cultured on coverslips were used for immunofluorescent analysis.

2.8. Western Blot. Cells were lysed in RIPA buffer supplemented with protease and phosphatase inhibitor cocktail (Cell Signaling Technology) and sonicated, and protein concentration was quantified by using Pierce BCA Protein Assay Kit (Thermo Fisher Scientific). Protein mixture was separated by SDS-PAGE and transferred to a nitrocellulose membrane $(0.2 \mu \mathrm{m})$. Membranes were blocked with blocking buffer and further incubated overnight at $4^{\circ} \mathrm{C}$ with the following antibodies: rabbit anti-mouse phospho-Akt (Ser473), NF- $\kappa$ B p65, pNF- $\kappa$ B p65 (Ser536), HIF-1 $\alpha$ (Cell Signaling Technology), polyclonal rabbit anti-mouse Nor1 (Abcam), and polyclonal goat anti-mouse $\mathrm{VEGF}_{164}$ antibody (R\&D Systems). After incubation with a HRP-conjugated goat anti-rabbit (Dako) or horse anti-goat (Vector Labs) secondary antibody membranes were developed with UptiLight HRP Blot Chemiluminescent ECL Substrate (Uptima). To normalize protein expression, blots were stripped and reprobed for GAPDH or $\beta$-actin and Akt, respectively, using a mouse anti-GAPDH antibody (Novus Biological) and anti-mouse $\beta$-actin and rabbit anti-mouse Akt antibody (Cell Signaling Technology).

2.9. ELISA. The levels of VEGF were quantified by ELISA using mouse DuoSet kits according to the manufacturer's instructions (R\&D Systems).

2.10. Ultrafiltration. Ultrafiltration units with various cutoffs (Vivaspin 6-20, Sartorius, Germany) were first rinsed by centrifuging pure water through the membrane. The medium to be analyzed was then centrifuged at $6000 \times g$ until the supernatant reached a tenth of its initial volume, and both the concentrated supernatant and filtrate fractions were collected in plastic tubes and used for experiments.

2.11. Statistical Analysis. Data were analyzed with GraphPad Prism 5 software. Experimental data are presented as means with standard error of the mean (SEM). Unpaired data of two groups were analyzed using the unpaired $t$-test. The onesample $t$-test was used when samples were compared with the reference control sample (set as 1). Normally distributed unpaired data of multiple groups were analyzed using oneway ANOVA with the Newman-Keuls post hoc test. A $p$ value less that 0.05 was considered statistically significant.

\section{Results}

3.1. Identification of Hypertrophy Markers in PE-Stimulated iPS-CM. Cardiac hypertrophy is manifested by numerous transcriptional, biochemical, and structural transformations including increased cell size, enhanced protein synthesis, and remodeling of the actin cytoskeleton. However, an in vitro hypertrophy model based on murine iPS-CM has not been described so far. Thus, we first started to identify gene markers in iPS-CM regulated by the hypertrophic substance PE. By performing microarray analysis, we found 154 genes to be regulated (fold change in expression $>2$ or $<-2$ ) by PE (Table 1, Figure 1(a)). Among the 46 upregulated 
TABle 1: Differential gene expression in PE-treated iPS-CM.

\begin{tabular}{|c|c|c|c|c|}
\hline Gene symbol & Gene ID & PE $100 \mu \mathrm{M}$ avg $(\log 2)$ & Control avg $(\log 2)$ & Fold change \\
\hline Nr4a3 & 1438796_at & 7.93 & 5.4 & 5.78 \\
\hline Creb3l1 & 1419295_at & 8.49 & 6.31 & 4.53 \\
\hline Mgarp & 1420774_a_at & 7.01 & 4.87 & 4.39 \\
\hline Dner & 1456379_x_at & 5.75 & 3.72 & 4.11 \\
\hline Pde4d & 1435280_at & 8.62 & 6.67 & 3.87 \\
\hline Inha & 1422728_at & 9.91 & 7.97 & 3.86 \\
\hline Dner & 1423671_at & 6.84 & 5.11 & 3.31 \\
\hline $\mathrm{Nppb}$ & 1450791_at & 9.94 & 8.22 & 3.3 \\
\hline Fam46a & 1437868_at & 9.58 & 7.93 & 3.14 \\
\hline Ajap1 & 1456197_x_at & 5.08 & 3.48 & 3.04 \\
\hline Scd1 & 1415964_at & 10.95 & 9.42 & 2.9 \\
\hline Slitrk4 & 1440516_at & 7.52 & 6.01 & 2.85 \\
\hline Cnn1 & 1417917_at & 10.04 & 8.6 & 2.72 \\
\hline Dgkk & 1442865_at & 7.08 & 5.68 & 2.66 \\
\hline Alpl & 1423611_at & 7.99 & 6.58 & 2.65 \\
\hline Clic6 & 1454866_s_at & 6.12 & 4.8 & 2.5 \\
\hline Mapk10 & 1437195_x_at & 6.56 & 5.26 & 2.46 \\
\hline Aqp4 & 1425382_a_at & 8.83 & 7.54 & 2.45 \\
\hline Ap1s3 & 1455735_at & 6.36 & 5.08 & 2.42 \\
\hline Slc16a3 & 1449005_at & 7.03 & 5.75 & 2.41 \\
\hline Greb1l & 1439341_at & 5.66 & 4.44 & 2.32 \\
\hline Rgs2 & 1419248_at & 8.42 & 7.22 & 2.3 \\
\hline Emilin2 & 1435264_at & 12 & 10.82 & 2.27 \\
\hline Bmp7 & 1418910_at & 7.54 & 6.39 & 2.22 \\
\hline Krt19 & 1417156_at & 5.43 & 4.28 & 2.22 \\
\hline Rgs2 & 1447830_s_at & 7.06 & 5.92 & 2.21 \\
\hline Slc7a3 & 1417022_at & 9.55 & 8.42 & 2.19 \\
\hline Sox11 & 1453125_at & 6.79 & 5.67 & 2.17 \\
\hline Pcdh8 & 1447825_x_at & 4.64 & 3.54 & 2.15 \\
\hline Slitrk4 & 1437744_at & 9.71 & 8.61 & 2.13 \\
\hline Fndc5 & 1453135_at & 6.77 & 5.68 & 2.12 \\
\hline Rgs2 & 1419247_at & 8.66 & 7.59 & 2.1 \\
\hline Pcdh8 & 1417051_at & 4.44 & 3.38 & 2.08 \\
\hline Bmp7 & 1432410_a_at & 6.67 & 5.62 & 2.07 \\
\hline Syt7 & 1460081_at & 8.3 & 7.26 & 2.06 \\
\hline Synm & 1457275_at & 7.98 & 6.93 & 2.06 \\
\hline Gp1bb & 1422977_at & 6.73 & 5.69 & 2.06 \\
\hline Bdh1 & 1452257_at & 9.86 & 8.83 & 2.04 \\
\hline Pmaip1 & 1418203_at & 8.49 & 7.46 & 2.04 \\
\hline Sox 11 & 1429372_at & 6.23 & 5.2 & 2.04 \\
\hline Kdelr3 & 1418538_at & 8.77 & 7.75 & 2.04 \\
\hline Fkbp11 & 1417267_s_at & 6.51 & 5.49 & 2.04 \\
\hline Olfml2b & 1423915_at & 10.71 & 9.68 & 2.03 \\
\hline Aqp4 & 1434449_at & 10.01 & 8.99 & 2.03 \\
\hline Sprrla & 1449133_at & 7.54 & 6.53 & 2.02 \\
\hline Synpo & 1427045_at & 8.17 & 7.16 & 2.02 \\
\hline Ddit4l & 1451751_at & 6.23 & 7.23 & -2 \\
\hline Maob & 1434354_at & 7.26 & 8.26 & -2 \\
\hline
\end{tabular}


TABle 1: Continued.

\begin{tabular}{|c|c|c|c|c|}
\hline Gene symbol & Gene ID & $\mathrm{PE} 100 \mu \mathrm{M}$ avg $(\log 2)$ & Control avg $(\log 2)$ & Fold change \\
\hline Mmp2 & 1416136_at & 5.97 & 6.97 & -2 \\
\hline Sema5a & 1434776_at & 6.18 & 7.18 & -2 \\
\hline Phkg1 & 1422315_x_at & 6.46 & 7.46 & -2.01 \\
\hline Kcnd2 & 1422834_at & 6.62 & 7.62 & -2.01 \\
\hline Ccdc187 & 1430052_at & 5.45 & 6.46 & -2.01 \\
\hline Fmod & 1437718_x_at & 4.98 & 5.98 & -2.01 \\
\hline Shisa9 & 1435424_x_at & 3.79 & 4.8 & -2.01 \\
\hline Cdo1 & 1448842_at & 9.23 & 10.24 & -2.01 \\
\hline Phkg1 & 1425164_a_at & 6.8 & 7.81 & -2.01 \\
\hline Epb4112 & 1459619_at & 5.89 & 6.91 & -2.01 \\
\hline Scn7a & 1436043_at & 8.07 & 9.08 & -2.02 \\
\hline Fbln 2 & 1423407_a_at & 6.62 & 7.63 & -2.02 \\
\hline Fmod & 1456084_x_at & 6.16 & 7.17 & -2.02 \\
\hline Clec2l & 1433764_at & 7.95 & 8.97 & -2.02 \\
\hline \multirow{4}{*}{ Prss35 } & 1434195_at & 4.2 & 5.22 & -2.03 \\
\hline & 1445148_at & 7.17 & 8.19 & -2.03 \\
\hline & 1446742_at & 3.72 & 4.74 & -2.03 \\
\hline & 1439174_at & 3.82 & 4.84 & -2.03 \\
\hline \multirow{2}{*}{ Tuba8 } & 1419518_at & 6.29 & 7.32 & -2.04 \\
\hline & 1440565_at & 5.79 & 6.81 & -2.04 \\
\hline Atpla2 & 1443823_s_at & 10.16 & 11.19 & -2.04 \\
\hline \multirow{2}{*}{ Parp8 } & 1442157_at & 4.55 & 5.58 & -2.04 \\
\hline & 1457338_at & 5.27 & 6.3 & -2.04 \\
\hline Scn7a & 1427495_at & 5.07 & 6.1 & -2.05 \\
\hline 4833420G17Rik & 1419637_s_at & 7.81 & 8.85 & -2.05 \\
\hline Rgs12 & 1429380_at & 6.68 & 7.71 & -2.05 \\
\hline Rgs4 & 1416286_at & 5.76 & 6.81 & -2.07 \\
\hline Socs2 & 1446085_at & 4.48 & 5.53 & -2.07 \\
\hline Dlk1 & 1449939_s_at & 8.7 & 9.75 & -2.07 \\
\hline \multirow{2}{*}{ Kcnj3 } & 1444025_at & 7.85 & 8.9 & -2.07 \\
\hline & 1445659_at & 4.08 & 5.14 & -2.07 \\
\hline Ctla2a, Ctla2b & 1416811_s_at & 4.16 & 5.22 & -2.08 \\
\hline $\operatorname{Tm} 4 \mathrm{sf1}$ & 1450958_at & 5.6 & 6.66 & -2.08 \\
\hline \multirow{2}{*}{ Ssbp2 } & 1429951_at & 6.91 & 7.97 & -2.09 \\
\hline & 1442609_at & 5.47 & 6.53 & -2.09 \\
\hline Gucyla3 & 1434141_at & 9.83 & 10.89 & -2.09 \\
\hline Cdh11 & 1450757_at & 8.41 & 9.47 & -2.09 \\
\hline Ptn & 1448254_at & 8.92 & 9.99 & -2.1 \\
\hline Col8a1 & 1455627_at & 6.76 & 7.83 & -2.1 \\
\hline Cdh11 & 1435120_at & 4.22 & 5.29 & -2.1 \\
\hline Socs3 & 1455899_x_at & 7.92 & 8.99 & -2.11 \\
\hline Dpm1 & 1459961_a_at & 6.05 & 7.14 & -2.12 \\
\hline Angpt1 & 1421441_at & 5.37 & 6.46 & -2.13 \\
\hline Col18a1 & 1426955_at & 8.21 & 9.3 & -2.13 \\
\hline Pcdh17 & 1436920_at & 7.42 & 8.51 & -2.14 \\
\hline Figf & 1438953_at & 5.95 & 7.05 & -2.14 \\
\hline Atpla2 & 1434893_at & 8.27 & 9.37 & -2.15 \\
\hline Cyr61 & 1457823_at & 9.73 & 10.84 & -2.15 \\
\hline
\end{tabular}


TABle 1: Continued.

\begin{tabular}{|c|c|c|c|c|}
\hline Gene symbol & Gene ID & $\mathrm{PE} 100 \mu \mathrm{M}$ avg $(\log 2)$ & Control avg $(\log 2)$ & Fold change \\
\hline Atp1a2 & 1427465_at & 9.12 & 10.23 & -2.15 \\
\hline Kcnip2 & 1436275_at & 5.85 & 6.96 & -2.16 \\
\hline Ano3 & 1443612_at & 3.87 & 5 & -2.18 \\
\hline Batf3 & 1453076_at & 4.8 & 5.92 & -2.18 \\
\hline Hmga2 & 1422851_at & 5.9 & 7.03 & -2.19 \\
\hline \multirow{2}{*}{ Figf } & 1449528_at & 6.74 & 7.88 & -2.19 \\
\hline & 1443551_at & 7.19 & 8.32 & -2.19 \\
\hline Bgn & 1448323_a_at & 6.99 & 8.13 & -2.2 \\
\hline Adamts5 & 1422561_at & 6.06 & 7.2 & -2.2 \\
\hline Scn7a & 1436044_at & 8 & 9.14 & -2.21 \\
\hline Olfm1 & 1425784_a_at & 7.02 & 8.16 & -2.21 \\
\hline Rufy3 & 1442786_s_at & 3.92 & 5.08 & -2.23 \\
\hline Cyr61 & 1442340_x_at & 10.04 & 11.21 & -2.24 \\
\hline Gucyla3 & 1420534_at & 7.06 & 8.22 & -2.24 \\
\hline Junb & 1415899_at & 9.02 & 10.19 & -2.25 \\
\hline Zfp36 & 1452519_a_at & 8.69 & 9.87 & -2.26 \\
\hline Fbln5 & 1416164_at & 6.08 & 7.25 & -2.26 \\
\hline Kctd12 & 1434881_s_at & 6.48 & 7.66 & -2.27 \\
\hline Cdc14a & 1436913_at & 4.4 & 5.59 & -2.28 \\
\hline Boc & 1426869_at & 5.77 & 6.98 & -2.31 \\
\hline Fam155a & 1435138_at & 5.08 & 6.29 & -2.31 \\
\hline Frem1 & 1455280_at & 5.83 & 7.07 & -2.36 \\
\hline 04. Sep & 1448729_a_at & 7.54 & 8.78 & -2.36 \\
\hline Ramp1 & 1431413_at & 6.08 & 7.32 & -2.37 \\
\hline Bgn & 1416405_at & 7.65 & 8.89 & -2.37 \\
\hline Asb14 & 1449547_at & 4.13 & 5.38 & -2.38 \\
\hline Lox & 1448228_at & 7.07 & 8.34 & -2.41 \\
\hline \multirow{3}{*}{ Socs 3} & 1456212_x_at & 7.34 & 8.61 & -2.42 \\
\hline & 1442813_at & 4.08 & 5.36 & -2.42 \\
\hline & 1439535_at & 7.43 & 8.71 & -2.42 \\
\hline Cpne5 & 1442166_at & 9.85 & 11.13 & -2.42 \\
\hline Edil3 & 1433474_at & 4.25 & 5.52 & -2.43 \\
\hline Iigp1 & 1419043_a_at & 6.02 & 7.3 & -2.43 \\
\hline Map3k8 & 1419208_at & 6.58 & 7.89 & -2.48 \\
\hline Col8a1 & 1418440_at & 5.65 & 6.99 & -2.53 \\
\hline Clca1; Clca3a1 & 1417852_x_at & 5.53 & 6.87 & -2.53 \\
\hline Igfbp2 & 1454159_a_at & 5.81 & 7.18 & -2.59 \\
\hline Asb15 & 1439836_at & 3.86 & 5.24 & -2.61 \\
\hline 04. Sep & 1455422_x_at & 6.53 & 7.94 & -2.65 \\
\hline Vgll3 & 1453593_at & 4.36 & 5.78 & -2.68 \\
\hline Ccdc187 & 1439194_at & 5.83 & 7.26 & -2.68 \\
\hline \multirow{2}{*}{ Skiv2l2 } & 1447517_at & 4.13 & 5.56 & -2.69 \\
\hline & 1445655_at & 5.35 & 6.83 & -2.79 \\
\hline Figf & 1438954_x_at & 5.54 & 7.03 & -2.81 \\
\hline Olfm1 & 1455796_x_at & 3.97 & 5.47 & -2.81 \\
\hline Egr2 & 1427683_at & 5.5 & 6.99 & -2.82 \\
\hline Ppp1r17 & 1449240_at & 5.16 & 6.66 & -2.84 \\
\hline Pdgfrb & 1436970_a_at & 4.57 & 6.12 & -2.93 \\
\hline
\end{tabular}


TABLE 1: Continued.

\begin{tabular}{|c|c|c|c|c|}
\hline Gene symbol & Gene ID & PE $100 \mu \mathrm{M}$ avg $(\log 2)$ & Control avg $(\log 2)$ & Fold change \\
\hline Lum & 1423607_at & 6.4 & 7.98 & -2.99 \\
\hline Arc & 1418687_at & 5.94 & 7.57 & -3.1 \\
\hline Cntn2 & 1435165_at & 6.09 & 7.75 & -3.16 \\
\hline Lox & 1416121_at & 7.48 & 9.15 & -3.19 \\
\hline Col3al & 1427884_at & 5.98 & 7.71 & -3.32 \\
\hline Egr2 & 1427682_a_at & 5.44 & 7.26 & -3.52 \\
\hline Sfrp5 & 1436075_at & 6.34 & 8.24 & -3.75 \\
\hline Pcdh17 & 1453070_at & 6.1 & 8.01 & -3.77 \\
\hline Unc80 & 1434989_at & 5.54 & 7.75 & -4.64 \\
\hline Egr3 & 1436329_at & 3.84 & 7.06 & -9.27 \\
\hline
\end{tabular}

genes, the gene Nr4a3, encoding for neuron-derived orphan receptor 1 (Nor1), was found to be the most upregulated gene ( 6-fold induction) in PE-treated iPS-CM. Upregulation of additional genes involved in hypertrophic cell growth, such as $N p p b$ (BNP), Myh7 ( $\beta$-MHC), Gjal (Cx43), and Nppa (ANP) [24], was lower when compared to Nor1/Nr4a3 expression levels (Figure 1(b)). On the basis of these results, we decided to use Nor1 as a valuable marker of hypertrophic cell growth in iPS-CM. The upregulation by PE was confirmed by real-time PCR (Figure 1(c)). In addition, Nor1 protein was significantly increased in hypertrophied iPS-CM, and increased activity of the kinase Akt, but not Erk, could be detected (Figure 1(d)). Nor1 expression showed a positive correlation with the cell surface area of iPS-CM evidenced by actin staining and immunofluorescence (Figure 1(e)).

3.2. Nor1 Expression and Akt Activation Are Mandatory for PE-Induced Hypertrophy in iPS-CM. To prove if Nor1 expression and Akt activation are important for hypertrophic cell growth, we suppressed Nor1 expression and Akt activity by using gene-specific siRNA or the pI3 kinase inhibitor wortmannin, respectively (Figure S1a-b), before treatment of cells with PE. No hypertrophic cell growth could be observed in the absence of Norl (Figure 2(a)) as well as in the case of suppressed Akt activity (Figure 2(b)) indicating that both Nor1 and activation of Akt are required for hypertrophy induction in iPS-CM. No effect on cell survival was observed (data not shown).

3.3. The Secretome of MSCs Induces Hypertrophy Regression in PE-Treated iPS-CM. Stimulation of bone marrowderived MSCs with IFN- $\gamma$ and IL- $1 \beta$ was accompanied by increased activation of NF- $\kappa \mathrm{B}$ as well as visible, but not significant, increase in intracellular HIF-1 $\alpha$ levels (Figure S2ab). As NF- $\kappa \mathrm{B}$ represents the main transcription factor controlling iNOS expression in response to IL-1 $\beta$ stimulation, nitrite levels were quantified in culture supernatants to validate preconditioning of MSCs [20]. Activation of NF- $\kappa \mathrm{B}$ usually results in the upregulation of genes involved in apoptosis, inflammation, and cellular adhesion, among others [25]. To further find out if preconditioned MSCs (acMSCs) influence hypertrophy in iPS-CM, PE-treated iPS-CM were cocultured with preconditioned MSCs by using a transwell system that prevents direct cell-cell interactions. The cell area of iPS$\mathrm{CM}$ was significantly reduced upon coculture with preconditioned MSCs, and similar results were obtained after medium supplementation with 20\% MSC-conditioned medium (Figure 3(a)). Of note, the observed effects of the MSC secretome on hypertrophied cells were found to be dose-dependent as medium supplementation with $10 \%$ conditioned medium or less did not result in hypertrophy regression (Figure S3). These results indicate that hypertrophy regression is mediated by MSC-derived soluble factors. Notably, hypertrophy regression was associated with downregulation of Nor1 protein expression in iPS-CM (Figure 3(b)).

We next aimed to identify MSC-derived molecules involved in the regression of hypertrophy. For this, we performed microarray analysis to enclose genes regulated by IFN- $\gamma$ and IL-1 $\beta$. A total of 2026 differentially regulated genes were identified; among them, 1037 were upregulated and 989 were downregulated (Figures 4(a)-4(c)). The top 100 list of significantly regulated genes ( $>2$-fold; $<-2$-fold change) is given in Table S1. In addition to many genes encoding for chemokines, iNOS and $I L-6$ were ranked in the top 30 upregulated genes (Figure 4(b)), supporting MSC activation and expression of immunomodulatory factors. Gene ontology (GO) enrichment analyzed by Metascape was used to categorize the upregulated gene networks in preconditioned MSCs (Figure 4(c)). The results suggest that the identified genes are largely involved in cellular responses to interferon-beta, interferon-gamma, cytokine production, and cytokine-mediated signaling pathways. In addition, some of the genes were involved in the regulation of the apoptotic pathway, regulation of DNA-binding transcription factor activity, and myeloid leukocyte activation.

To further identify MSC-derived molecules which are potentially involved in hypertrophy regression, the supernatant of preconditioned MSCs was concentrated and fractionated by using Vivaspin centrifugal devices with a molecular mass cutoff of $30 \mathrm{kDa}, 50 \mathrm{kDa}$, and $100 \mathrm{kDa}$. Both the concentrates and the filtrates, containing small molecules, were used to explore their effects on hypertrophied iPS-CM. Histological analysis revealed that all concentrates used for 


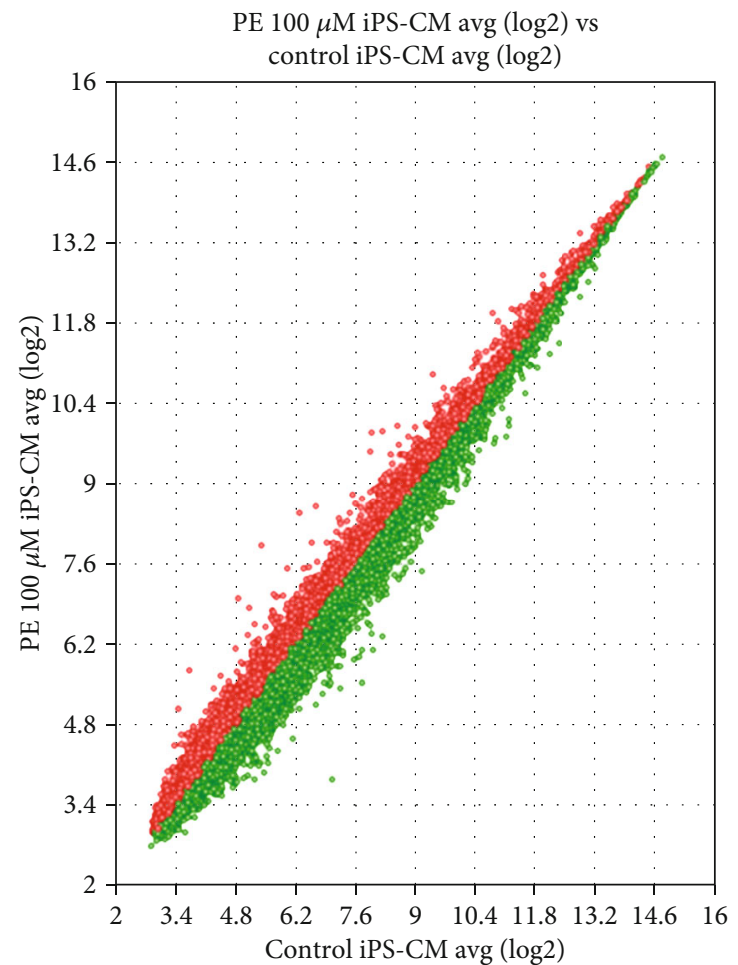

(a)
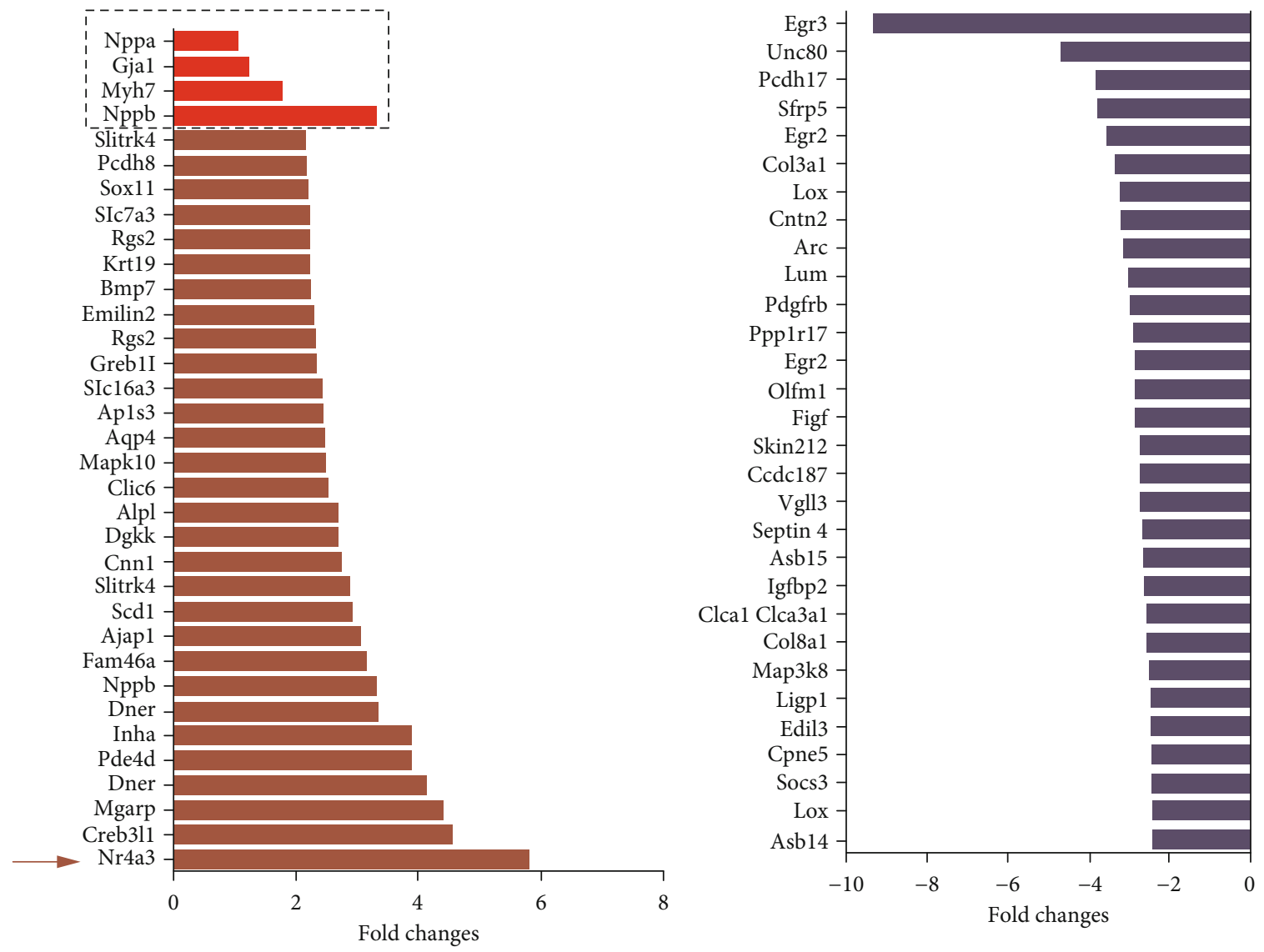

(b)

Figure 1: Continued. 


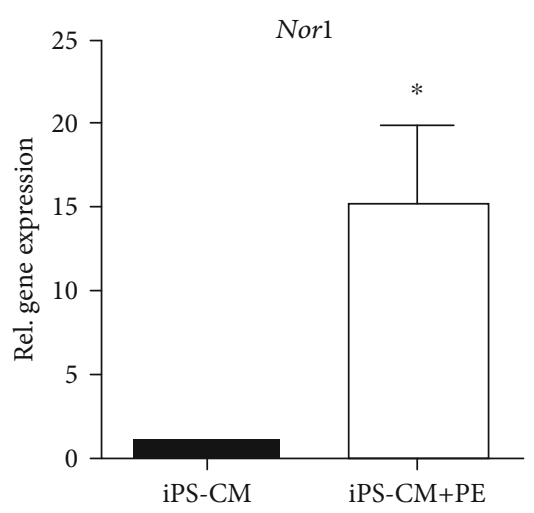

(c)
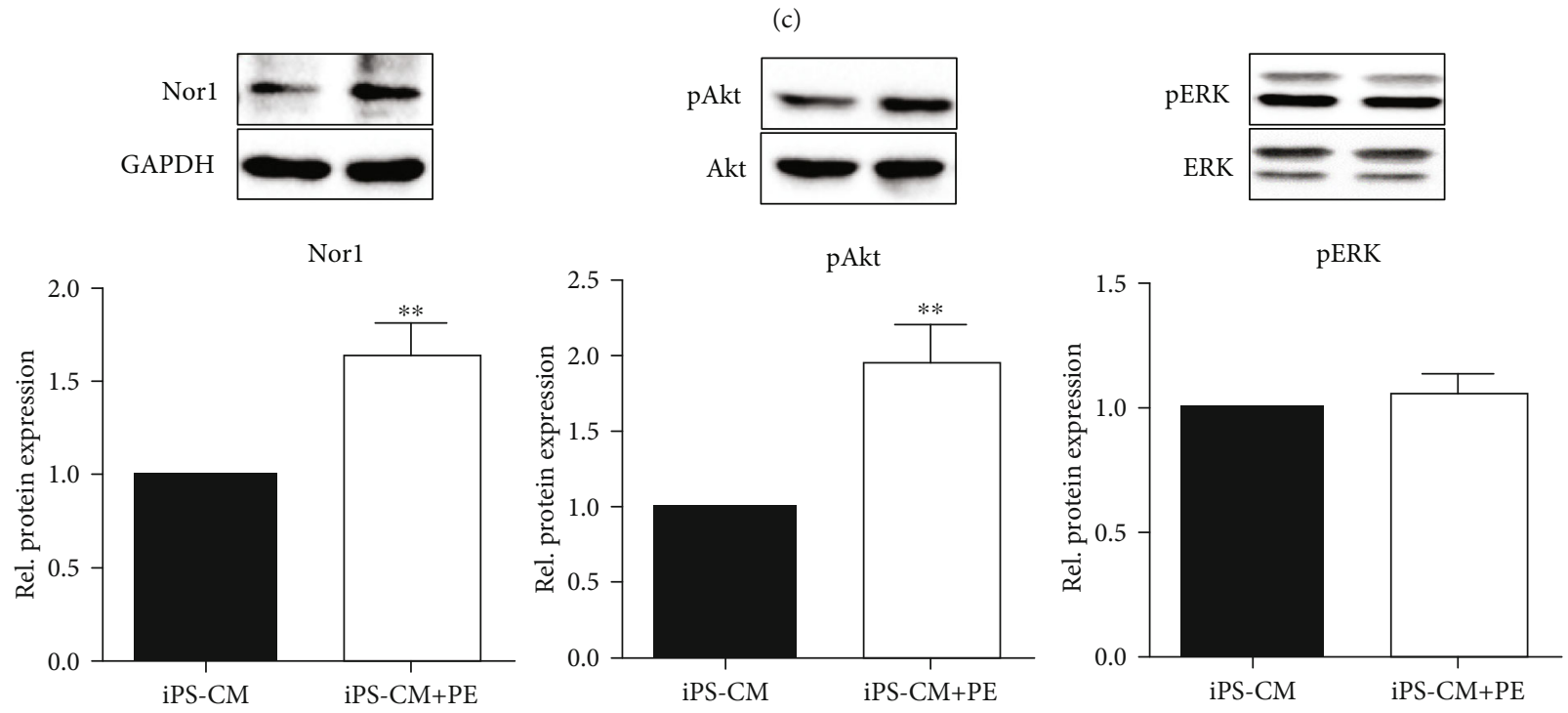

(d)
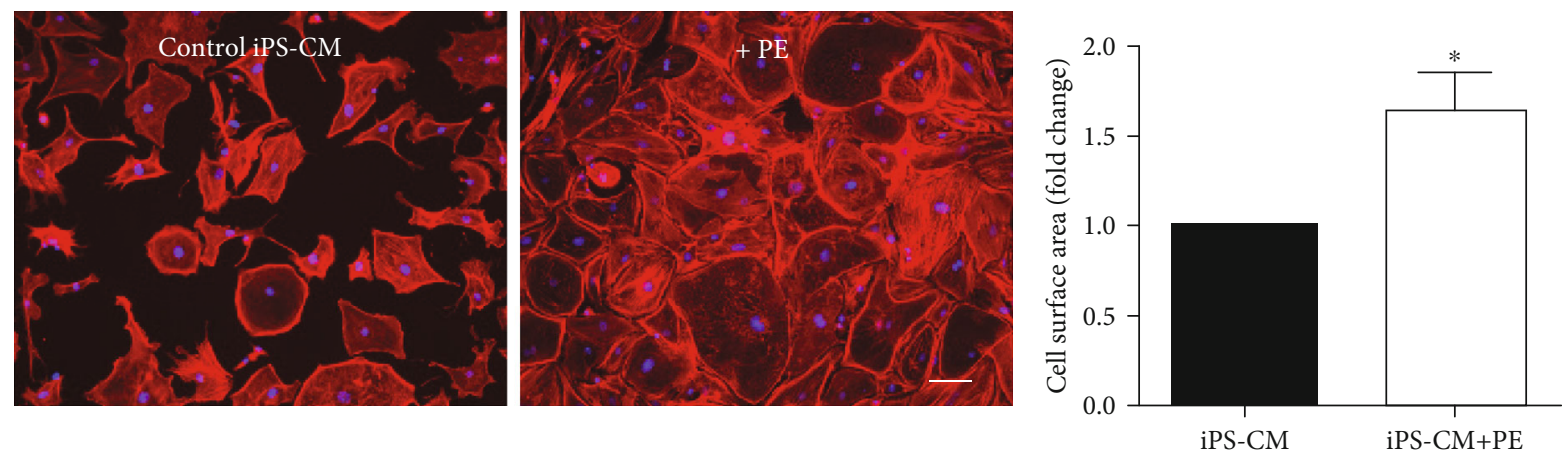

(e)

Figure 1: Characterization of hypertrophied iPS-CM. iPS-CM were cultured in the presence of $100 \mu \mathrm{M}$ phenylephrine (PE) to induce hypertrophy. (a) Scatter plot of microarray data showing log2 of the gene transcripts between iPS-CM and iPS-CM treated with PE. (b) Top 30 up- and downregulated genes in PE-treated iPS-CM. Additional significantly upregulated genes involved in hypertrophic cell growth are highlighted by the dotted square. (c) Nor1 gene expression was verified by real-time PCR. $n=5$. (d) Western blot analysis of Nor1 $(n=8)$, normalized to the expression levels of GAPDH. The expression of phosphorylated Akt (pAkt, $n=8)$ and phosphorylated Erk (pERK, $n=4$ ) in hypertrophied iPS-CM was normalized to that of the unphosphorylated forms. (e) iPS-CM were seeded on fibronectincoated coverslips and treated with $100 \mu \mathrm{M}$ PE for $24 \mathrm{~h}$. Cells were further fixed and incubated with Alexa Fluor 555 phalloidin to stain intracellular F-actin (red). Nuclei were counterstained with DAPI (blue), and the cell area was quantified microscopically. Bar: $100 \mu \mathrm{m}$; $n$ $=7 .{ }^{*} p<0.05,{ }^{* *} p<0.01$.

experiments significantly reversed hypertrophy in iPS-CM. In turn, protective effects in cells treated with filtrates were visibly reduced (Figure 5(a)). Nor1 expression in iPS-CM showed a good correlation with the cell area when cells were treated with the fraction containing molecules $<30 \mathrm{kDa}$ ( $30 \mathrm{kDa}$ filtrate) and the corresponding concentrate, whereby 

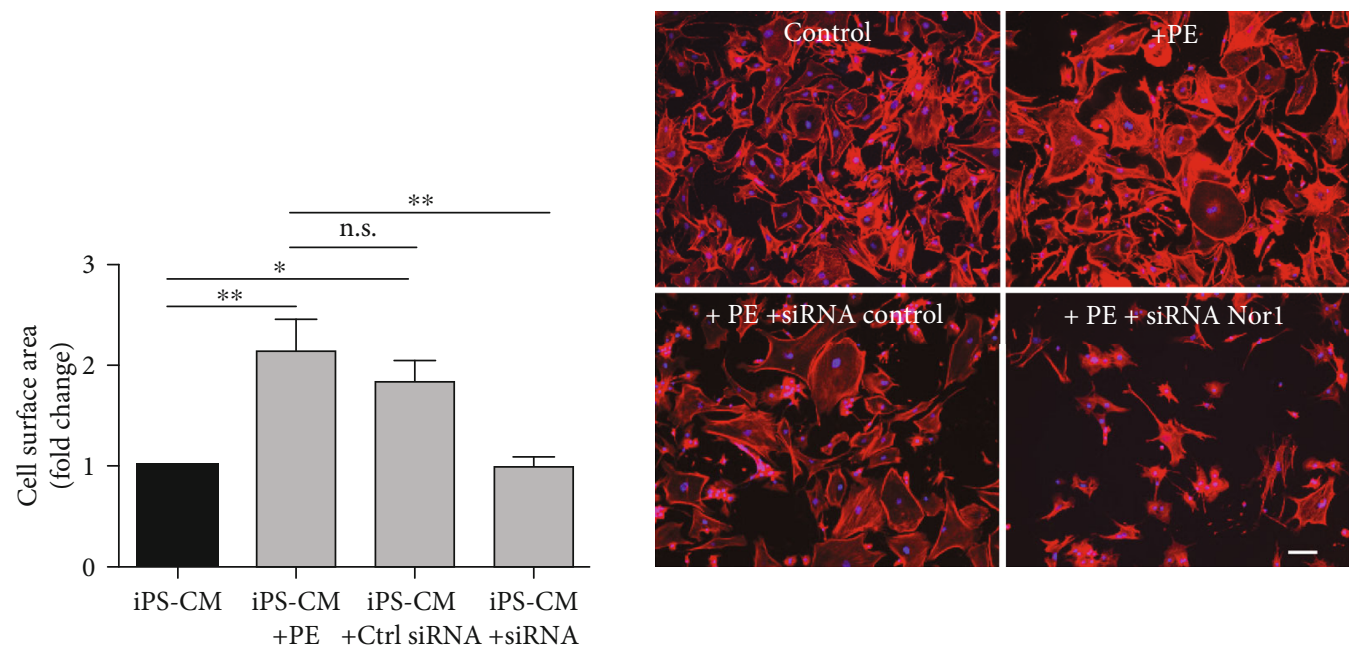

(a)
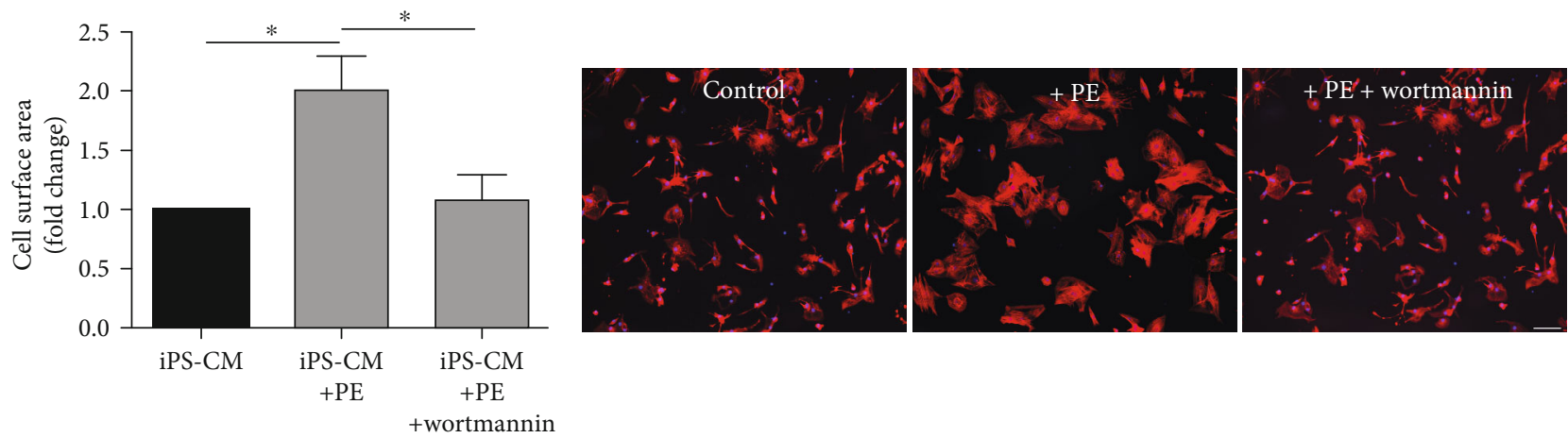

(b)

FIGURE 2: Suppression of Nor1 and Akt activity prevents hypertrophy induction in iPS-CM. (a) iPS-CM were seeded on fibronectin-coated coverslips and transfected with Nor1 siRNA or control siRNA, respectively. After $24 \mathrm{~h}$, cells were further treated with PE (100 $\mu \mathrm{M})$ to induce hypertrophy. iPS-CM cell size was quantified by histological staining of F-actin (red). $n=4$. (b) iPS-CM were treated with wortmannin $(400 \mathrm{nM})$ before hypertrophy induction by PE. Cell size was quantified by staining of the actin cytoskeleton. Representative images are depicted. Bar: $100 \mu \mathrm{m} . n=4$. n.s. $=$ not significant; ${ }^{*} p<0.05,{ }^{* *} p<0.01$.

differences in protein expression were not significantly altered (Figure 4(b)).

3.4. VEGF Secreted by Preconditioned MSCs Reverses Hypertrophy in PE-Treated iPS-CM and Downregulates Nor1 Gene Expression. VEGF secreted by bone marrowderived MSCs was recently reported to reverse hypertrophic cell growth $[26,27]$. Having found that molecules involved in hypertrophy reduction seem to be larger than $30 \mathrm{kDa}$, we next determined if preconditioned MSCs represent a potential source for VEGF. Significant 5.8-fold upregulation of Vegfa expression after MSC preconditioning could be detected by microarray analysis (data not shown). VEGF levels were visibly elevated in the supernatants of preconditioned MSCs $24 \mathrm{~h}$ as well as $48 \mathrm{~h}$ after cytokine stimulation. Moreover, VEGF was detected in all ultrafiltration concentrates (Figure 6(a)) which were previously found to induce hypertrophy regression in iPS-CM (Figure 5(a)). The antihypertrophic effects of MSC-conditioned medium as well as of the medium fraction containing molecules $>30 \mathrm{kDa}$ were strongly mitigated after VEGF inactivation by VEGF- neutralizing antibodies (Figure 6(b)). VEGF neutralization in MSC-conditioned medium increased Nor1 expression in iPS-CM, although significant increase in Nor1 protein levels could not be detected (Figure 6(c)).

As these results do not exclude the possibility that VEGF may derive from the hypertrophied iPS-CM themselves, we further tested if VEGF expression in iPS-CM becomes regulated by the MSC-conditioned medium. As shown in Figure 6(d), intracellular VEGF protein could be detected in both MSCs and iPS-CM; however, no effect of MSCconditioned medium on VEGF expression in iPS-CM could be observed. Additionally, neither PE treatment nor culture in the presence of MSC-conditioned medium provoked an increase in VEGF secretion by iPS-CM (Figure 6(e)), suggesting that preconditioned MSCs represent the main source for VEGF.

\section{Discussion}

In this study, we demonstrate for the first time that Nor1 represents an essential molecule for hypertrophy induction in 

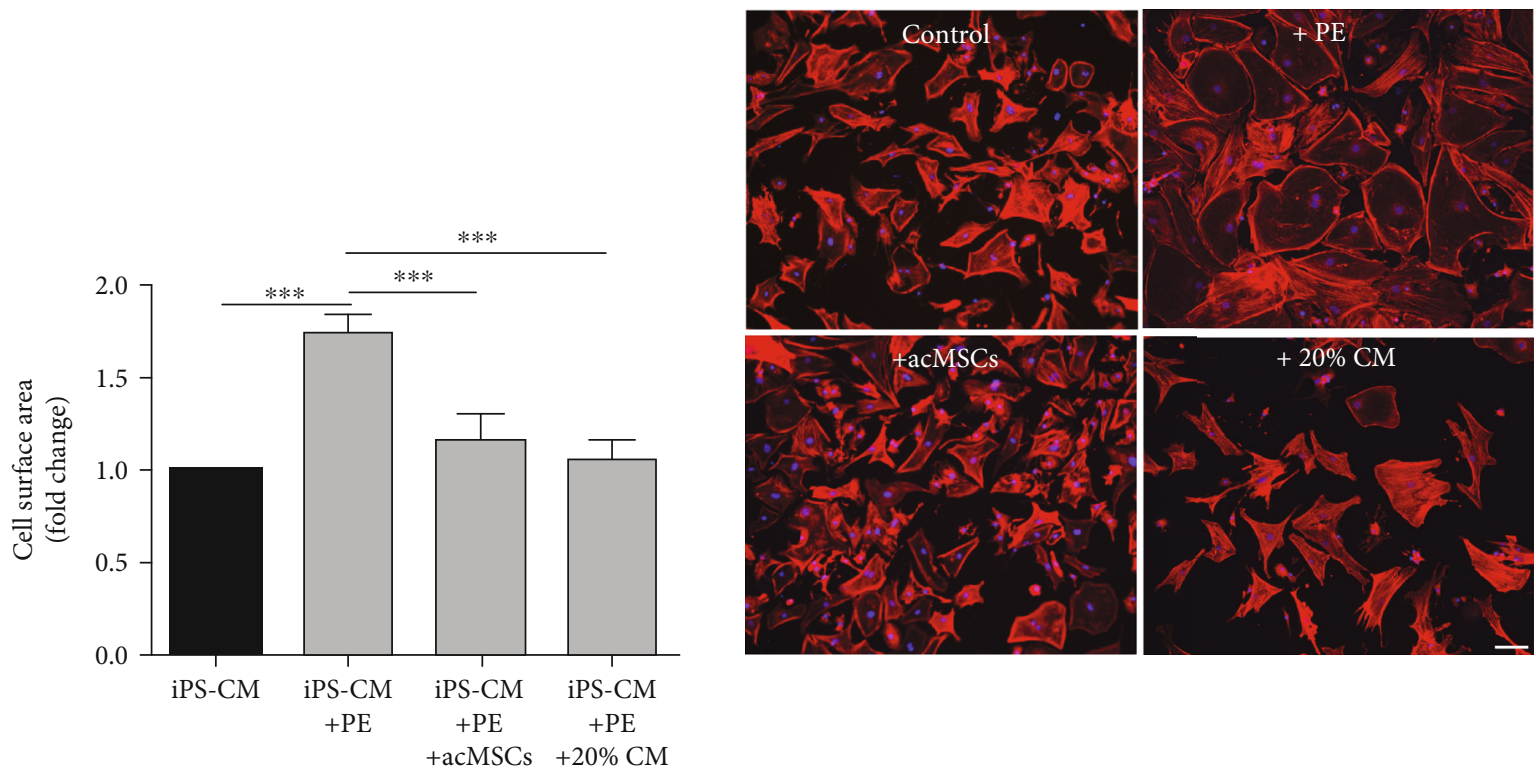

(a)
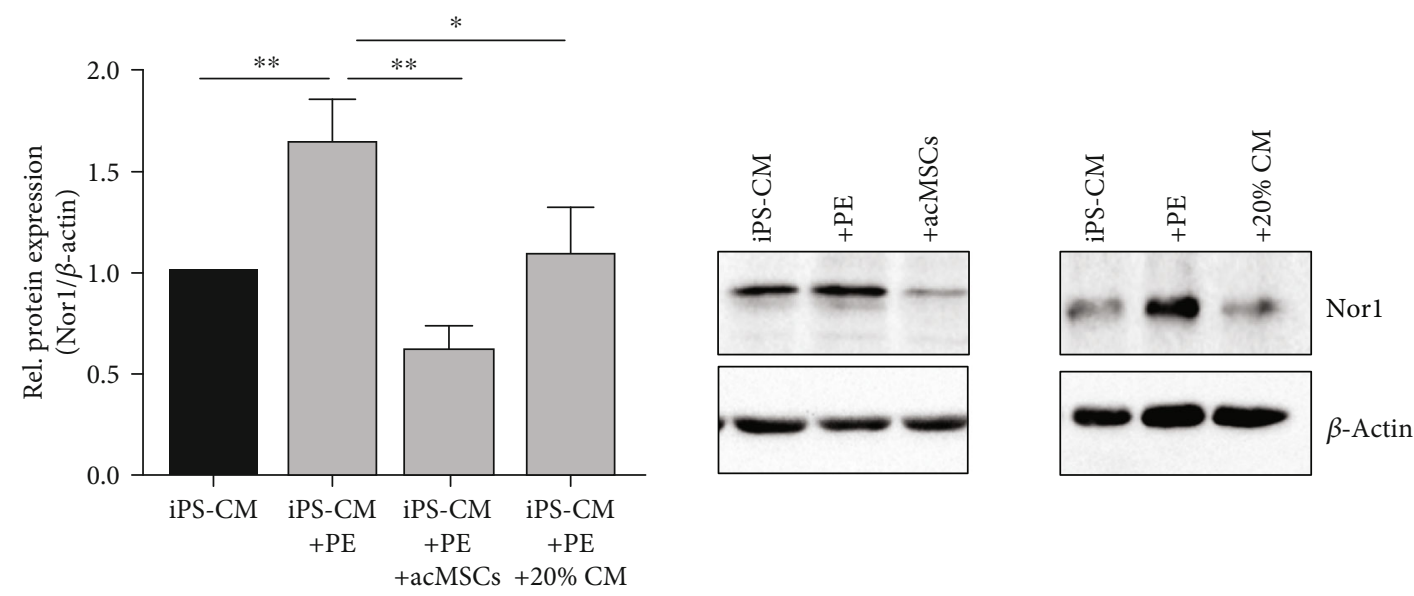

(b)

FIGURE 3: MSC-derived soluble mediators induce hypertrophy regression in iPS-CM. Bone marrow-derived MSCs were stimulated with $30 \mathrm{ng} / \mathrm{ml} \mathrm{IFN}-\gamma$ and $3 \mathrm{ng} / \mathrm{ml} \mathrm{IL-} 1 \beta$ for $24 \mathrm{~h}$. Then, preconditioned MSCs (acMSCS) were indirectly cocultured with hypertrophied iPSCM. In some experiments, hypertrophied iPS-CM were cultured in medium supplemented with 20\% MSC-conditioned medium (CM). (a) Cell area quantification in iPS-CM was performed by immunofluorescent staining. Representative images are displayed. Bar: $100 \mu \mathrm{m}$. $n=6$ . (b) Nor1 protein expression in iPS-CM. $n=5 .{ }^{*} p<0.05,{ }^{* *} p<0.01$, and ${ }^{* * *} p<0.001$.

iPS-CM. Further, our data indicate that among others, VEGF secreted by preconditioned murine bone marrow-derived MSCs is effective in reducing hypertrophy in iPS-CM. VEGF-mediated hypertrophy regression strongly correlated with a reduction in Nor 1 gene expression. Thus, delivery of MSC-conditioned medium as well as intrinsic suppression of Nor1 expression might represent suitable, cell-free strategies to reverse cardiac hypertrophy.

In this study, we established an in vitro model of cardiac hypertrophy on the basis of murine iPS-CM. Stimulation of cells with the hypertrophic substance PE increased cell size and induced significant upregulation of the nuclear receptor Nor1. However, upregulation of other key hypertrophy genes like $N p p a$ (atrial natriuretic factor, ANF), Nppb (brain natriuretic peptide, BNP), Gjal (connexin 43), and Myh7 ( $\beta$-myo- sin heavy chain) was much weaker, indicating that Nor1 represents the most feasible hypertrophy marker in iPSCM. Several reports suggest that Nor1 is involved in the pathophysiology of cardiac hypertrophy and heart failure, although very little is known about the underlying molecular mechanisms. Knockdown of Nor1 has been reported to prevent isoprenaline-induced hypertrophy in rat cardiomyocytes, whereas Nor1 overexpression exacerbated cardiac hypertrophy in vitro and in vivo $[9,10]$. In this regard, it is assumed that Nor1 upregulates the expression of hypertrophy markers and additionally promotes PARP-1 activation, resulting in functional impairment and progression of cardiac hypertrophy and heart failure [9]. Although we did not investigate the mechanism by which Nor1 regulates hypertrophy in iPS-CM, we found that silencing of Nor1 


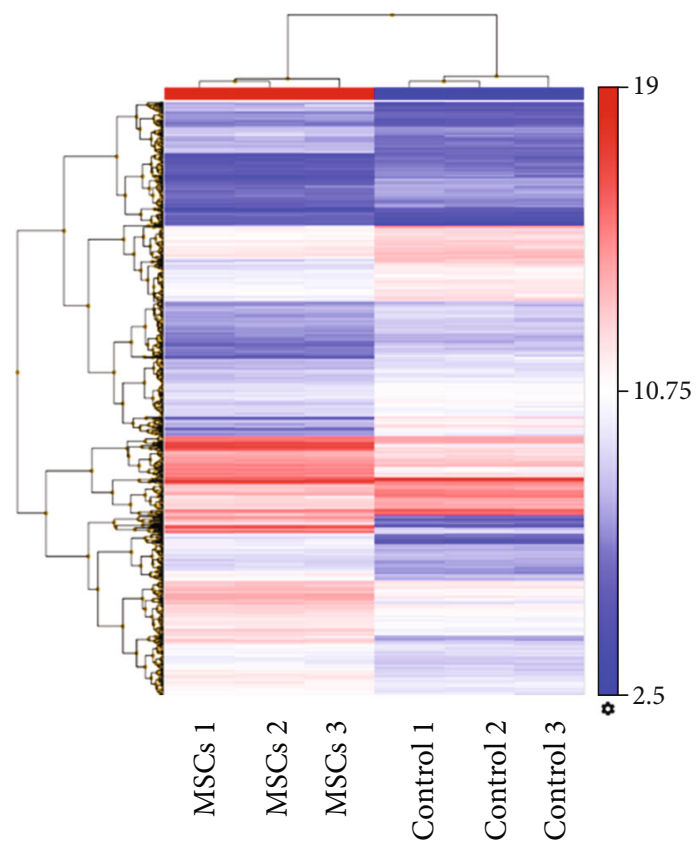

(a)

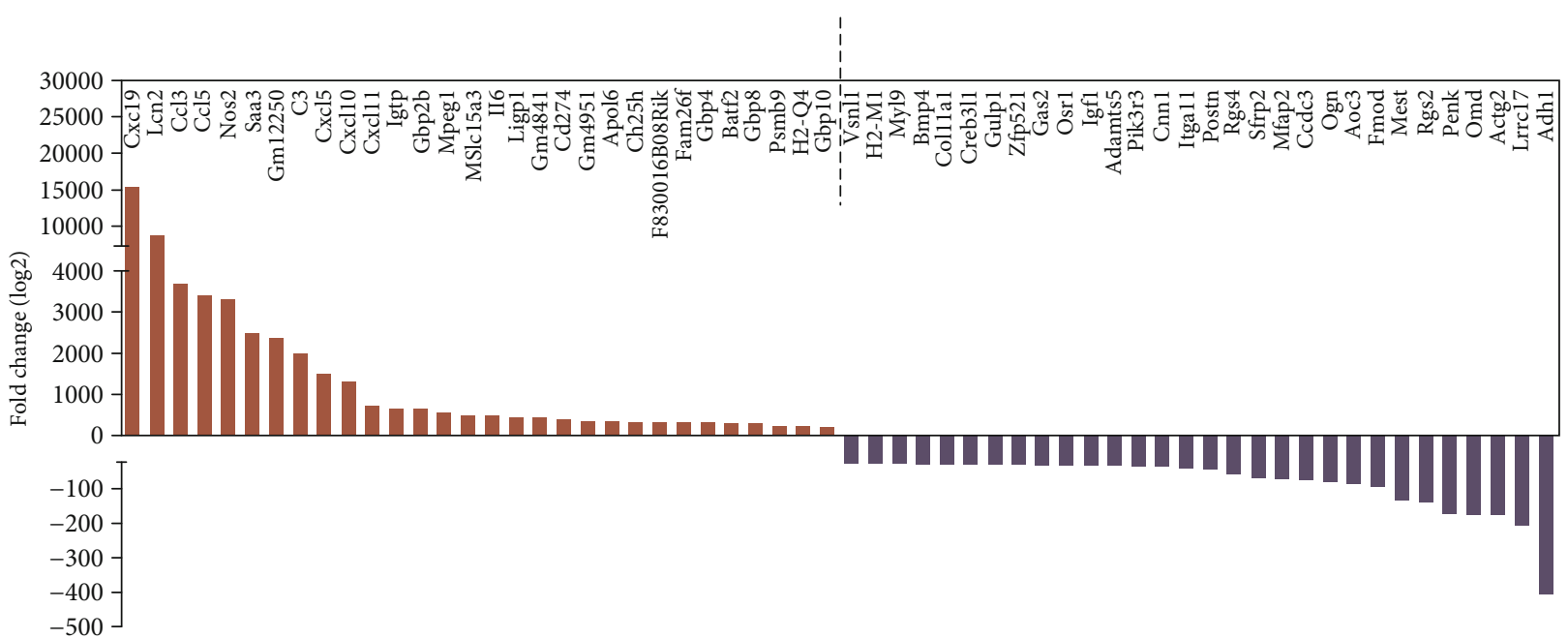

(b)

FIgUre 4: Continued. 


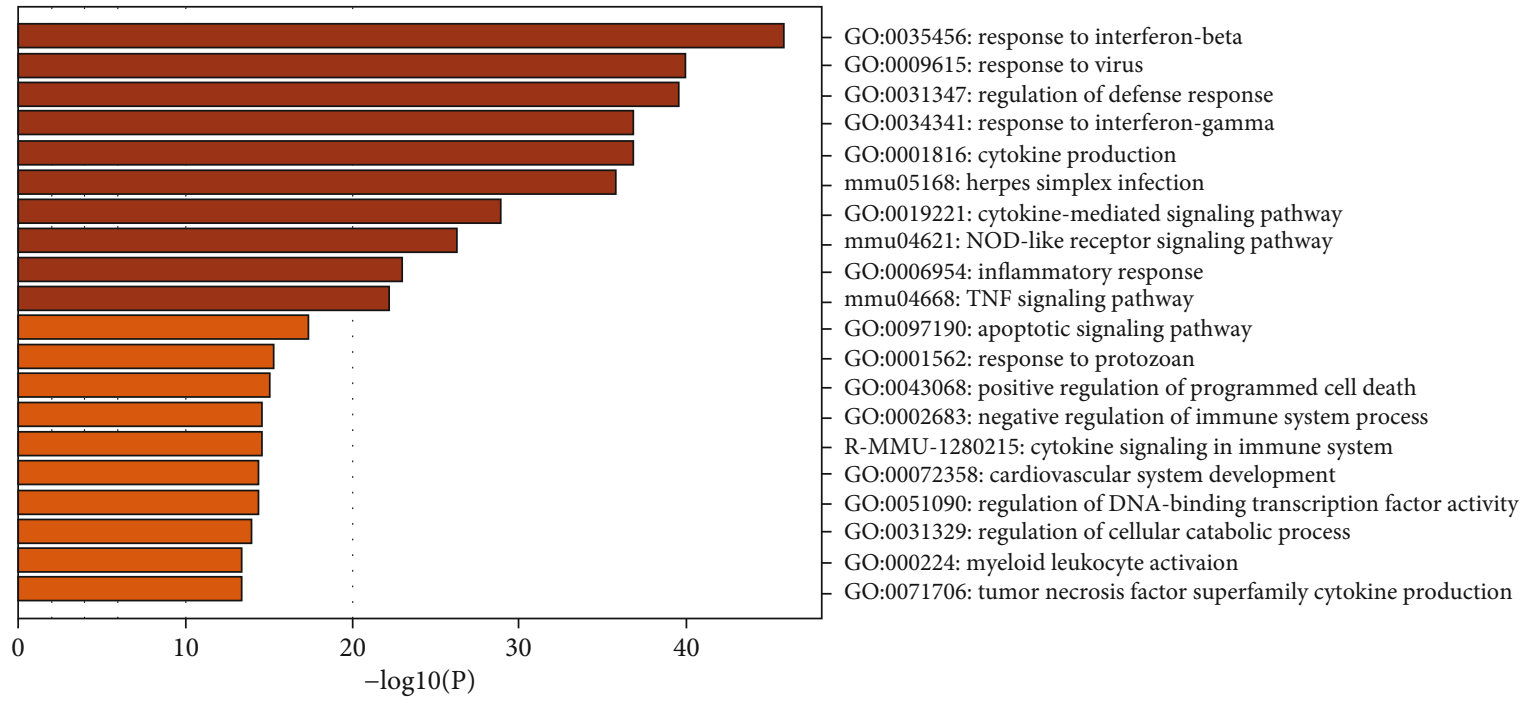

(c)

FIGURE 4: Microarray analysis highlighting differentially expressed genes in preconditioned MSCs. (a) Heatmap representing gene expression in MSCs with and without preconditioning. (b) Top 30 of up- and downregulated genes in MSCs after preconditioning. (c) GO enrichment analysis for upregulated genes in preconditioned MSCs.

expression by siRNA completely inhibited hypertrophy induction in a similar way as the pI3K inhibitor wortmannin. Thus, Nor1 expression as well as pI3K/Akt activation is fundamental for hypertrophic cell growth although the involvement of additional factors could be expected.

In the past decade, MSCs have been recognized to represent one of the most promising cellular therapies for cardiovascular diseases due to their ability to self-renew in a longterm manner and the capacity to differentiate into diverse specialized cell types. Additionally, there is a large body of evidence showing that MSCs secrete a variety of biologically active molecules such as growth factors, chemokines, and cytokines [28].

Preconditioning of MSCs greatly improves their proliferative, secretory, and migratory abilities and their abilities to differentiate [22]. Here, we present data demonstrating that preconditioned bone marrow-derived MSCs as well as MSC-conditioned medium promote hypertrophy regression in iPS-CM indicating that this effect is solely dependent on soluble mediators. Importantly, initial experiments demonstrated that MSCs without preconditioning do not lead to hypertrophy regression in iPS-CM after indirect coculture. MSC preconditioning by IFN- $\gamma$ and IL- $1 \beta$ led to significant upregulation of NF- $\kappa \mathrm{B}$ and consequently induced upregulation of over 1000 genes, most of them encoding for chemokines and cytokines. Hence, both IL- $1 \beta$ and IFN- $\gamma$ were reported to promote NF- $\kappa \mathrm{B}$-dependent accumulation of HIF- $1 \alpha$ under normoxic conditions $[29,30]$. As we further found that the molecular weight of these molecules seems to be larger than $30 \mathrm{kDa}$, we further concluded that most of the upregulated chemokines (molecular weight $\sim 10 \mathrm{kDa}$ ) can be excluded as mediators of the protective effects. In fact, many factors such as CCL-2, CCL-3, and CCL-5, whose gene expression was highly increased in preconditioned MSCs, were reported to be upregulated in patients with structural remodeling including hypertrophy and congestive heart disease [31]. Moreover, it has previously been found by Jung et al. that HIF- $1 \alpha$ is involved in the regulation of VEGF via a pathway dependent on NF- $\kappa \mathrm{B}$ [29].

The role of VEGF in cardiac hypertrophy is controversially discussed. On the one hand, VEGF was demonstrated to drive cardiac hypertrophy [32] whereby, on the other hand, VEGF-mediated hypertrophy regression was largely attributed to its ability to increase cardiac angiogenesis [33, 34]. Although MSCs produce remarkable amounts of VEGF $[26,35,36]$, VEGF secretion was significantly upregulated by MSC preconditioning. All concentrates of MSCconditioned medium containing VEGF reversed hypertrophy in iPS-CM, indicating that VEGF induces hypertrophy regression. However, it should be noted that VEGF was identified in all concentrates although concentrators with different cutoffs were used in this study. These results might be explained by the absorbance of the protein to the membrane or the plastic surface of the device. On the basis of the generated results, we cannot exclude that additional MSC-derived soluble molecules may exert antihypertrophic effects by synergistic or additive interactions with VEGF.

VEGF neutralization attenuated the protective effect of MSC-conditioned medium, and upregulation of Nor1 could be detected at the same time. Additionally, our data do not support the findings of Cai et al. who described a synergistic increase in extracellular VEGF after coculturing hypertrophied cardiomyocytes and bone marrow-derived MSCs [26]. Neither intracellular VEGF upregulation in iPS-CM nor increased VEGF secretion was detected after treatment of cells with MSC-conditioned medium or after indirect coculture, respectively. These observations suggest that preconditioned MSCs seem to represent the main source for VEGF which in turn reverses hypertrophy by suppressing Nor1 expression in cardiomyocytes. 


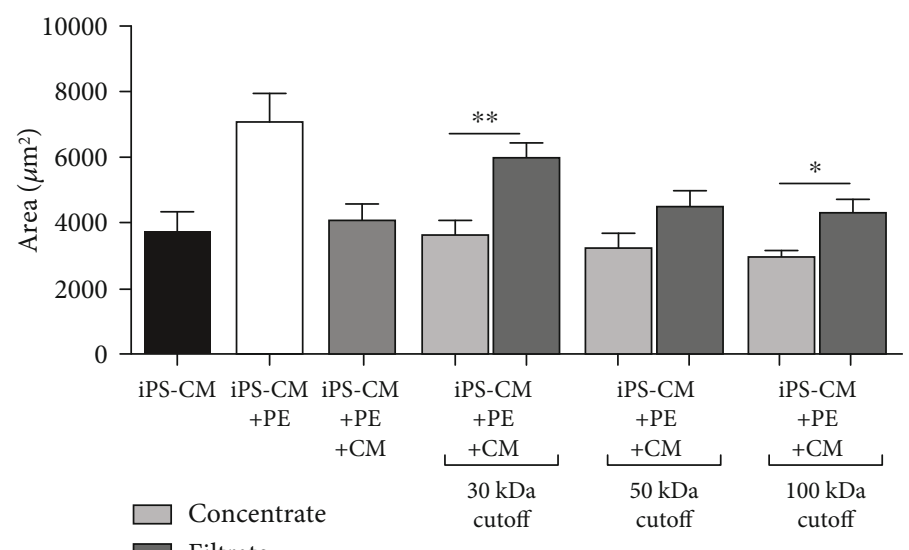

(a)

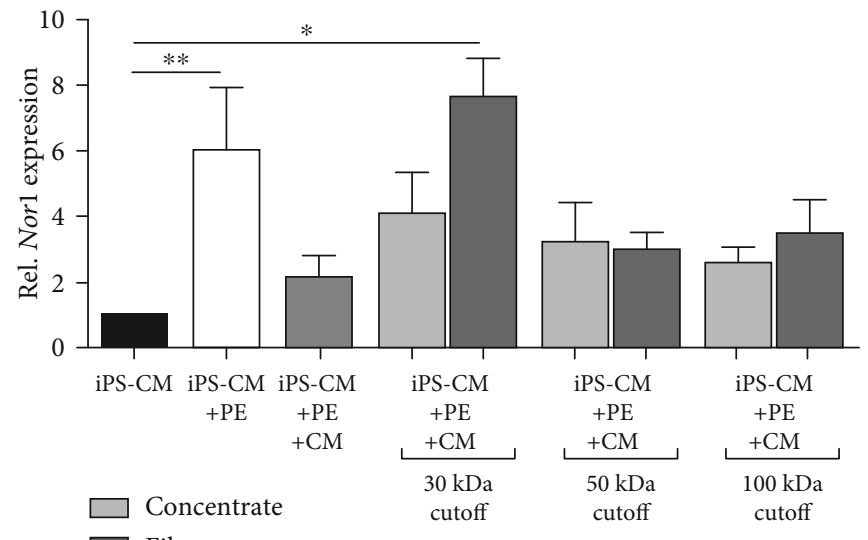

(b)
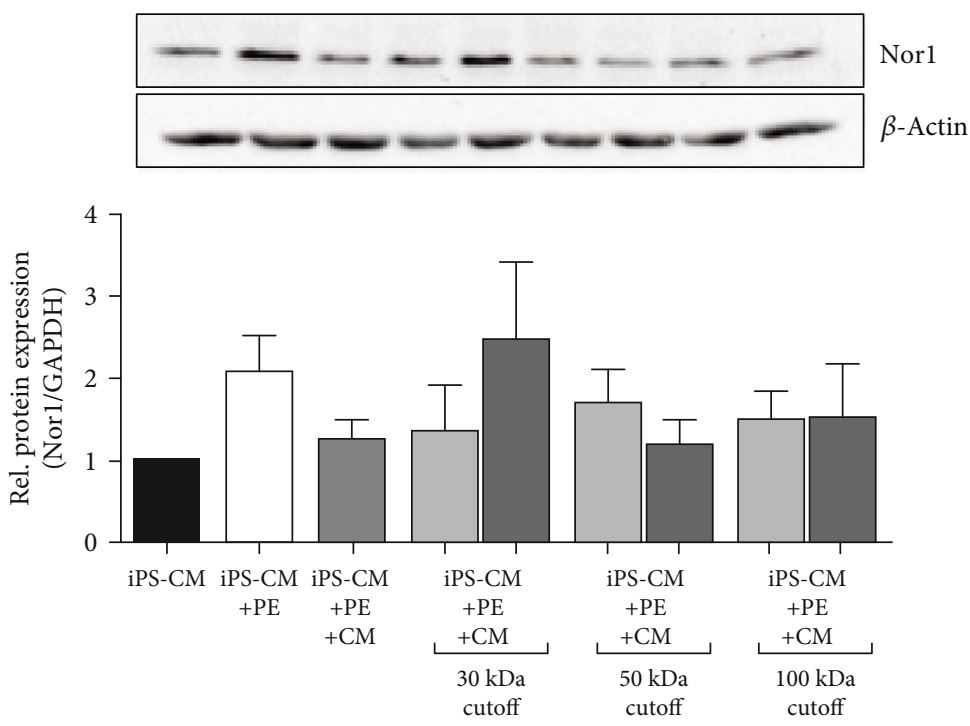

(c)

FIGURE 5: Hypertrophy regression in iPS-CM is mediated by soluble factors larger than $30 \mathrm{kDa}$. Culture supernatant from preconditioned MSCs was fractionated by ultrafiltration using columns with $30 \mathrm{kDa}, 50 \mathrm{kDa}$, and $100 \mathrm{kDa}$ cutoff. Hypertrophied iPS-CM were treated with the different concentrates and the corresponding filtrates for $24 \mathrm{~h}$. MSC-conditioned medium (CM) was used as a control. (a) Quantification of the cell surface area by immunofluorescence. $n=10$. Nor1 gene (b) and protein (c) expression was quantified in iPS-CM. $n=5 .{ }^{*} p<0.05,{ }^{* *} p<0.01$. 

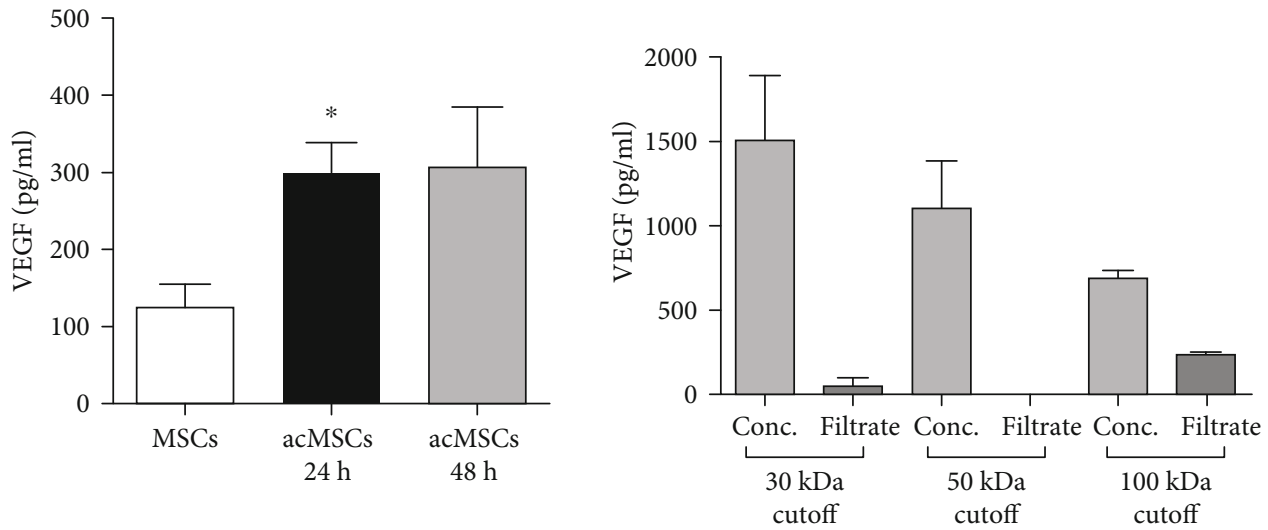

(a)
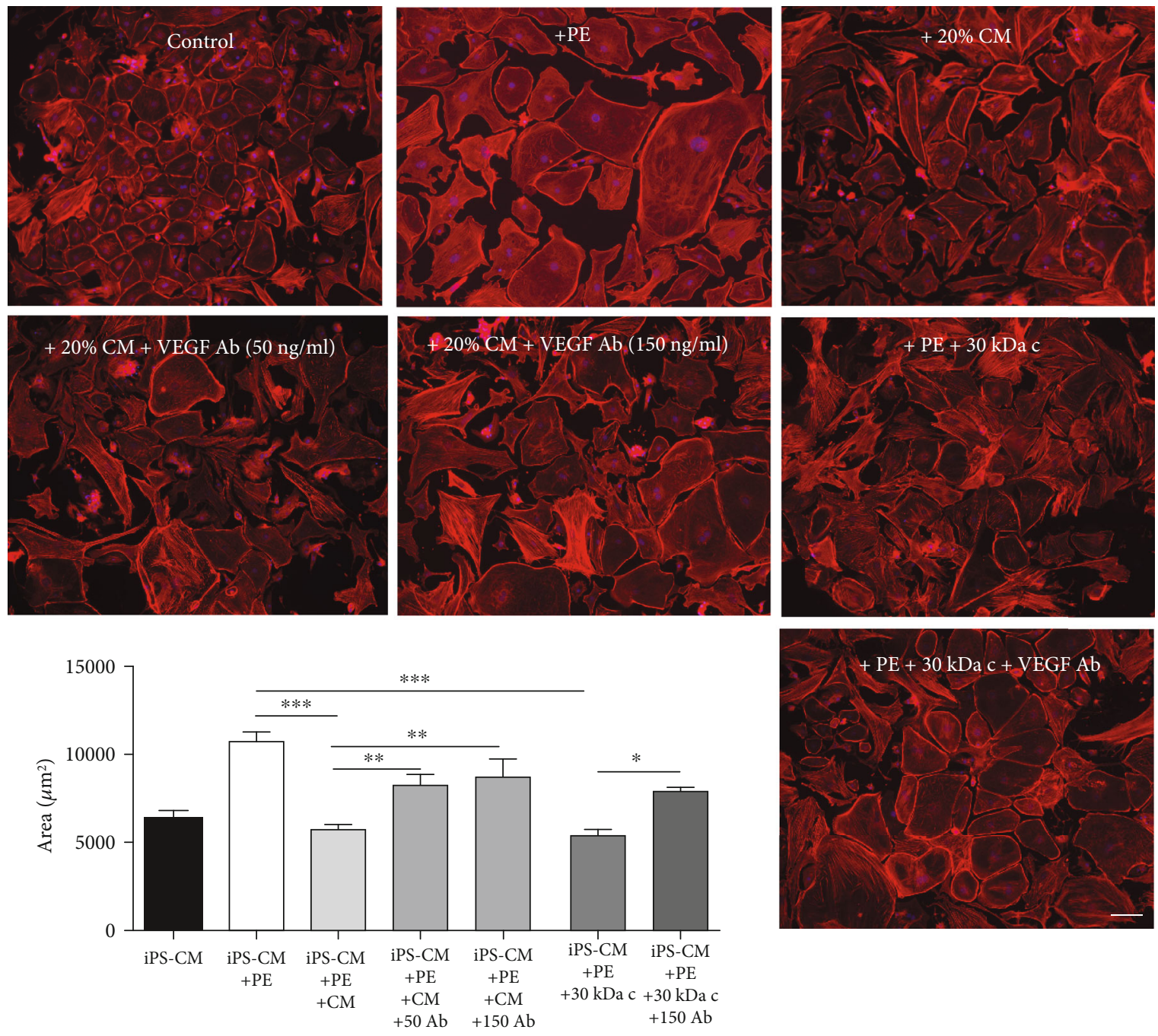

(b)

Figure 6: Continued. 

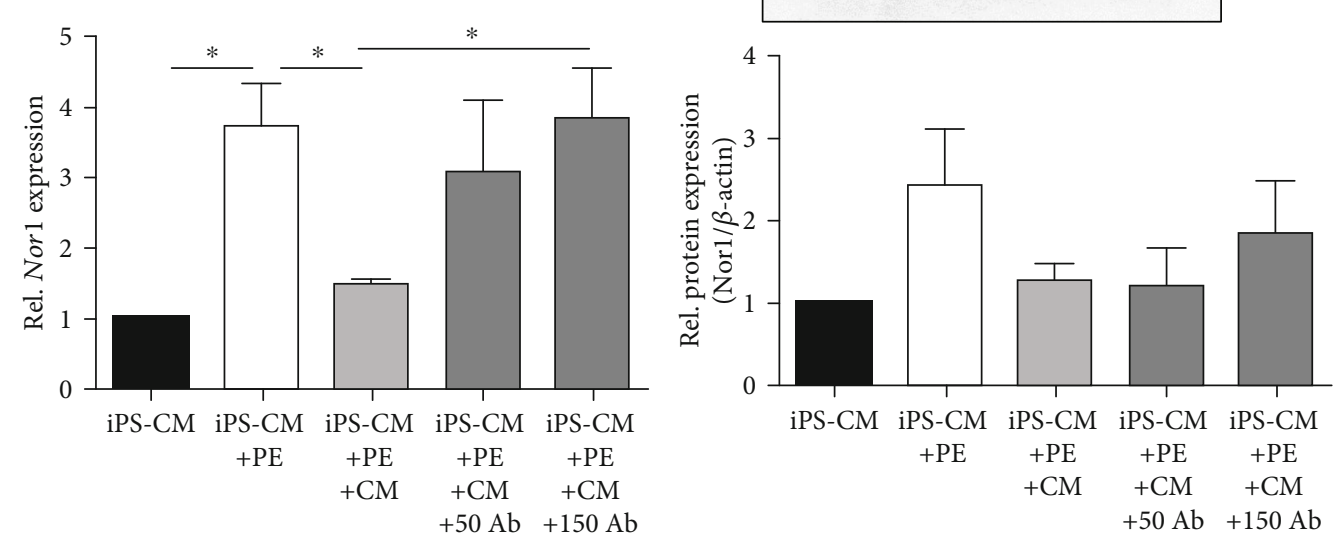

(c)
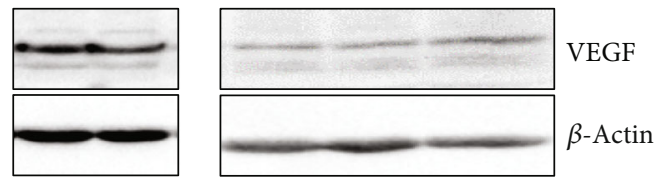

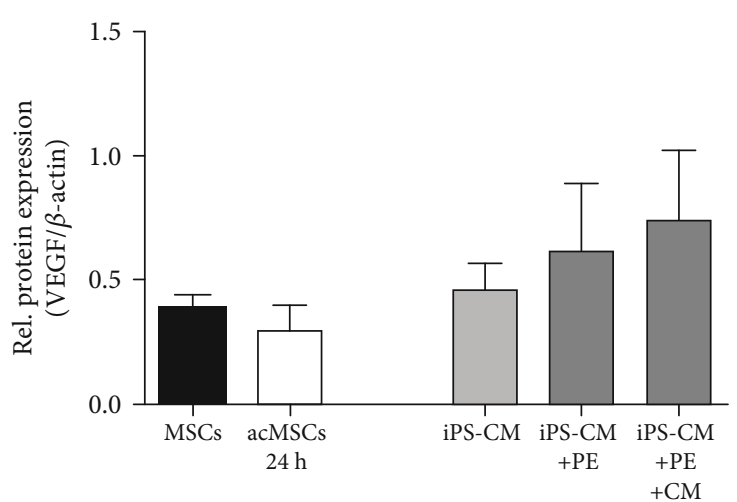

(d)

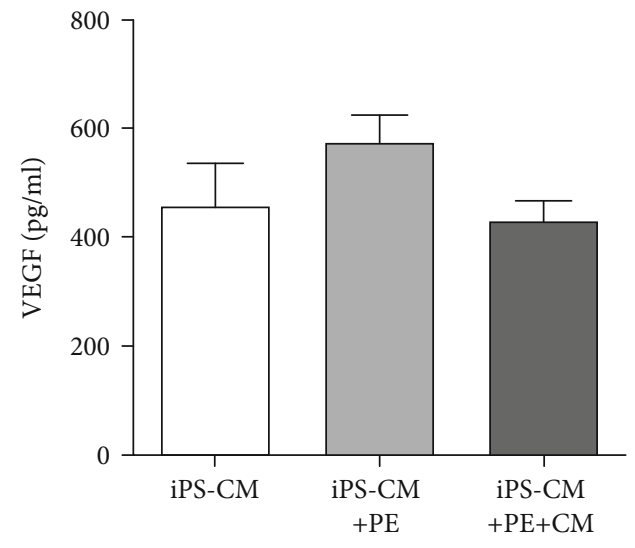

(e)

FIGURE 6: MSC-derived VEGF is essential for hypertrophy regression in iPS-CM. (a) VEGF was quantified in culture supernatants of MSCs stimulated with $30 \mathrm{ng} / \mathrm{ml} \mathrm{IFN}-\gamma$ and $3 \mathrm{ng} / \mathrm{ml} \mathrm{IL}-1 \beta$ for $24 \mathrm{~h}$ and those cultured for additional $24 \mathrm{~h}$ in serum-free medium ( $48 \mathrm{~h}$ ). In addition, VEGF levels in fractionated MSC-conditioned medium (concentrates and filtrates) were determined by ELISA. $n=5$. (b) PE-treated hypertrophied iPS-CM were cultured in the presence of $20 \%$ MSC-conditioned medium (CM) for $24 \mathrm{~h}$. As a control, cells were cultured in medium supplemented with $>30 \mathrm{kDa}$ concentrates. For VEGF neutralization, $50 \mathrm{ng} / \mathrm{ml}$ or $150 \mathrm{ng} / \mathrm{ml}$ neutralizing anti-VEGF antibodies was added to the culture medium. The cell surface area was quantified by F-actin staining. Representative images are displayed. Bar: $100 \mu \mathrm{m} . n=5$. (c) Nor1 gene and protein expression was quantified in iPS-CM cultured in the presence of MSC-CM supplemented with VEGF-neutralizing antibodies. $n=4$. (d) Intracellular VEGF levels were quantified in hypertrophied iPS-CM cultured in the presence of $20 \% \mathrm{CM}$ for $24 \mathrm{~h}$. MSCs with and without preconditioning served as a control. $n=4$. (e) VEGF levels were quantified in culture supernatants of PE-treated iPS-CM cultured in medium supplemented with $20 \% \mathrm{CM}$ for $24 \mathrm{~h} . n=6 .{ }^{*} p<0.05,{ }^{* *} p<0.01$, and ${ }^{* * *} p<0.001$.

In this regard, beside contributing to the formation of new vessels, VEGF has additionally been described to induce M1 macrophages to shift to an M2 phenotype [37] and to attenuate cardiac hypertrophy $[26,38]$. Thus, the beneficial effects of VEGF in vivo are expected to be manifold including direct antihypertrophic effects on cardiomyocytes, macrophage transpolarization into an anti-inflammatory phenotype [37], and angiogenesis [33]. In the light of these results, cytokine preconditioning should be considered a tool to increase the therapeutic efficacy of bone marrow-derived MSCs.

However, there are some limitations in the present study that need to be addressed. First, our study was limited by the use of adult bone marrow-derived MSCs with reduced selfrenewal and differentiation capacity, high variations between different batches, and progressive cell senescence [39-41]. Second, the secretome of MSCs also appears to vary significantly, depending on the age of the host, health status, and 
niches where the cells reside. Besides, NF- $\kappa \mathrm{B}$ was previously reported to be critical for the secretion of cytokines and growth factors by MSCs, and several studies proposed that genetic modification of MSCs may improve NK- $\kappa \mathrm{B}$ signaling and their paracrine activities $[42,43]$. Although we provided evidence for NF- $\kappa$ B activation in preconditioned MSCs, the onset of NF- $\kappa$ B activation may markedly differ between different MSC preparations. Further, we did not consider the complexity of the MSC secretome including microvesicles, microRNAs, exosomes, and mitochondrial transfer among others [44]. The limitations may be largely omitted by the development of more attractive strategies on the basis of iPS cell-derived MSCs. These cells were demonstrated to have higher proliferative capacity, higher telomerase activity, and lower cell senescence than bone marrow-derived MSCs allowing generation of highly homogenous populations without loss of functional quality $[39,45]$.

Altogether, the results of our study indicate that conditioned medium from IFN- $\gamma$ - and IL- $1 \beta$-stimulated MSCs may represent an appropriate therapeutic approach for the treatment of LVH. Nevertheless, further studies are needed to characterize preconditioned iPS cell-derived MSCs and to evaluate the efficacy and safety of secretome components for the treatment of cardiac hypertrophy in vivo.

\section{Conclusions}

Preconditioning of bone marrow-derived MSCs with IL- $1 \beta$ and IFN- $\gamma$ strongly improves their paracrine actions. Moreover, VEGF secreted by MSCs reverses Nor1-dependent hypertrophy in iPS-CM. Altogether, delivery of MSCconditioned medium may represent a promising cell-free therapeutic approach for the treatment of LVH although in vivo efficacy requires further investigation.

\section{Data Availability}

The datasets supporting the conclusions of this article are available from the corresponding author upon reasonable request.

\section{Conflicts of Interest}

The authors declare that they have no competing interests.

\section{Authors' Contributions}

Denise Philipp and Michelle Holthaus contributed equally to this work.

\section{Acknowledgments}

We thank Natalia Mierau, Sabine Schmitt, and Ellen Veit for their excellent technical assistance. This study was in part supported by a grant from the German Heart Research Foundation (to A.P.G. and T.W., \#F/06/16) and a grant from the German Research Foundation (to K.P.).

\section{Supplementary Materials}

Supplementary Figure S1: supplementary figure showing suppression of Nor1 expression and inhibition of Akt activity by siRNA transfection and wortmannin treatment, respectively. Supplementary Figure S2: supplementary figure showing NF- $\kappa \mathrm{B}$ activation and HIF- $1 \alpha$ upregulation in preconditioned MSCs. Supplementary Figure S3: supplementary figure showing hypertrophy regression in iPS-CM after incubation with different concentrations of MSCconditioned medium. Supplementary Table S1: supplementary table showing the top 100 of up- and downregulated genes in preconditioned MSCs determined by microarray analysis. (Supplementary Materials)

\section{References}

[1] N. Frey, H. A. Katus, E. N. Olson, and J. A. Hill, "Hypertrophy of the heart: a new therapeutic target?," Circulation, vol. 109, no. 13, pp. 1580-1589, 2004.

[2] B. H. Lorell and B. A. Carabello, "Left ventricular hypertrophy," Circulation, vol. 102, no. 4, pp. 470-479, 2000.

[3] F. Kuwahara, H. Kai, K. Tokuda et al., "Hypertensive myocardial fibrosis and diastolic dysfunction: another model of inflammation?," Hypertension, vol. 43, no. 4, pp. 739-745, 2004.

[4] C. Tsioufis, P. Stougiannos, A. Kakkavas et al., "Relation of left ventricular concentric remodeling to levels of C-reactive protein and serum amyloid $\mathrm{A}$ in patients with essential hypertension," The American Journal of Cardiology, vol. 96, no. 2, pp. 252-256, 2005.

[5] W. Hanif, L. Alex, Y. Su et al., "Left atrial remodeling, hypertrophy, and fibrosis in mouse models of heart failure," Cardiovascular Pathology, vol. 30, pp. 27-37, 2017.

[6] D. D. Schocken, E. J. Benjamin, G. C. Fonarow et al., "Prevention of heart failure: a scientific statement from the American Heart Association Councils on Epidemiology and Prevention, Clinical Cardiology, Cardiovascular Nursing, and High Blood Pressure Research; Quality of Care and Outcomes Research Interdisciplinary Working Group; and Functional Genomics and Translational Biology Interdisciplinary Working Group," Circulation, vol. 117, no. 19, pp. 2544-2565, 2008.

[7] C. M. van Tiel and C. J. M. de Vries, "NR4All in the vessel wall," The Journal of Steroid Biochemistry and Molecular Biology, vol. 130, no. 3-5, pp. 186-193, 2012.

[8] F. De Paoli, J. Eeckhoute, C. Copin et al., "The neuron-derived orphan receptor 1 (NOR1) is induced upon human alternative macrophage polarization and stimulates the expression of markers of the M2 phenotype," Atherosclerosis, vol. 241, no. 1, pp. 18-26, 2015.

[9] X. J. Feng, H. Gao, S. Gao et al., "The orphan receptor NOR1 participates in isoprenaline-induced cardiac hypertrophy by regulating PARP-1," British Journal of Pharmacology, vol. 172, no. 11, pp. 2852-2863, 2015.

[10] L. Cañes, I. Martí-Pàmies, C. Ballester-Servera et al., "Neuronderived orphan receptor-1 modulates cardiac gene expression and exacerbates angiotensin II-induced cardiac hypertrophy," Clinical Science, vol. 134, no. 3, pp. 359-377, 2020.

[11] S. Heymans, M. F. Corsten, W. Verhesen et al., "Macrophage microRNA-155 promotes cardiac hypertrophy and failure," Circulation, vol. 128, no. 13, pp. 1420-1432, 2013. 
[12] T. M. Lee, H. J. Harn, T. W. Chiou et al., "Remote transplantation of human adipose-derived stem cells induces regression of cardiac hypertrophy by regulating the macrophage polarization in spontaneously hypertensive rats," Redox Biology, vol. 27, p. 101170, 2019.

[13] A. Rolf, B. Assmus, V. Schächinger et al., "Maladaptive hypertrophy after acute myocardial infarction positive effect of bone marrow-derived stem cell therapy on regional remodeling measured by cardiac MRI," Clinical Research in Cardiology, vol. 100, no. 11, pp. 983-992, 2011.

[14] A. R. Williams and J. M. Hare, "Mesenchymal stem cells: biology, pathophysiology, translational findings, and therapeutic implications for cardiac disease," Circulation Research, vol. 109, no. 8, pp. 923-940, 2011.

[15] V. Karantalis, D. L. DiFede, G. Gerstenblith et al., “Autologous mesenchymal stem cells produce concordant improvements in regional function, tissue perfusion, and fibrotic burden when administered to patients undergoing coronary artery bypass grafting: the Prospective Randomized Study of Mesenchymal Stem Cell Therapy in Patients Undergoing Cardiac Surgery (PROMETHEUS) trial," Circulation Research, vol. 114, no. 8, pp. 1302-1310, 2014.

[16] J. Bartunek, A. Behfar, D. Dolatabadi et al., "Cardiopoietic stem cell therapy in heart failure: the C-CURE (Cardiopoietic stem Cell therapy in heart failURE) multicenter randomized trial with lineage-specified biologics," Journal of the American College of Cardiology, vol. 61, no. 23, pp. 2329-2338, 2013.

[17] F. Drey, Y. H. Choi, K. Neef et al., "Noninvasive in vivo tracking of mesenchymal stem cells and evaluation of cell therapeutic effects in a murine model using a clinical 3.0 T MRI," Cell Transplantation, vol. 22, no. 11, pp. 1971-1980, 2013.

[18] L. Fan, C. Hu, J. Chen, P. Cen, J. Wang, and L. Li, "Interaction between mesenchymal stem cells and B-cells," International Journal of Molecular Sciences, vol. 17, no. 5, p. 650, 2016.

[19] B. Zhang, R. Liu, D. Shi et al., "Mesenchymal stem cells induce mature dendritic cells into a novel Jagged-2-dependent regulatory dendritic cell population," Blood, vol. 113, no. 1, pp. 4657, 2009.

[20] D. Philipp, L. Suhr, T. Wahlers, Y. H. Choi, and A. PaunelGorgulu, "Preconditioning of bone marrow-derived mesenchymal stem cells highly strengthens their potential to promote IL-6-dependent M2b polarization," Stem Cell Research \& Therapy, vol. 9, no. 1, p. 286, 2018.

[21] Y. Guo, Y. Yu, S. Hu, Y. Chen, and Z. Shen, “The therapeutic potential of mesenchymal stem cells for cardiovascular diseases," Cell Death \& Disease, vol. 11, no. 5, p. 349, 2020.

[22] C. Hu and L. Li, "Preconditioning influences mesenchymal stem cell properties in vitro and in vivo," Journal of Cellular and Molecular Medicine, vol. 22, no. 3, pp. 1428-1442, 2018.

[23] J. Semmler, M. Lehmann, K. Pfannkuche, M. Reppel, J. Hescheler, and F. Nguemo, "Functional expression and regulation of hyperpolarization-activated cyclic nucleotide-gated channels (HCN) in mouse iPS cell-derived cardiomyocytes after UTF1-neo selection," Cellular Physiology and Biochemistry, vol. 34, no. 4, pp. 1199-1215, 2014.

[24] C. Peng, X. Luo, S. Li, and H. Sun, "Phenylephrine-induced cardiac hypertrophy is attenuated by a histone acetylase inhibitor anacardic acid in mice," Molecular BioSystems, vol. 13, no. 4, pp. 714-724, 2017.

[25] J. Caamano and C. A. Hunter, "NF-kappaB family of transcription factors: central regulators of innate and adaptive immune functions," Clinical Microbiology Reviews, vol. 15, no. 3, pp. 414-429, 2002.

[26] B. Cai, X. Tan, Y. Zhang et al., "Mesenchymal stem cells and cardiomyocytes interplay to prevent myocardial hypertrophy," Stem Cells Translational Medicine, vol. 4, no. 12, pp. 14251435, 2015.

[27] R. Liufu, G. Shi, X. He et al., "The therapeutic impact of human neonatal BMSC in a right ventricular pressure overload model in mice," Stem Cell Research \& Therapy, vol. 11, no. 1, p. 96, 2020.

[28] A. Fierabracci, A. Del Fattore, and M. Muraca, "The immunoregulatory activity of mesenchymal stem cells: 'state of art' and 'future avenues'," Current Medicinal Chemistry, vol. 23, no. 27, pp. 3014-3024, 2016.

[29] Y. J. Jung, J. S. Isaacs, S. Lee, J. Trepel, and L. Neckers, "IL1beta-mediated up-regulation of HIF-1alpha via an NFkappaB/COX-2 pathway identifies HIF-1 as a critical link between inflammation and oncogenesis," The FASEB Journal, vol. 17, no. 14, pp. 2115-2117, 2003.

[30] S. Yang, M. Yu, L. Sun et al., "Interferon- $\gamma$-induced intestinal epithelial barrier dysfunction by NF- $\kappa \mathrm{B} / \mathrm{HIF}-1 \alpha$ pathway," Journal of Interferon \& Cytokine Research, vol. 34, no. 3, pp. 195-203, 2014.

[31] P. Aukrust, T. Ueland, F. Muller et al., "Elevated circulating levels of C-C chemokines in patients with congestive heart failure," Circulation, vol. 97, no. 12, pp. 1136-1143, 1998.

[32] A. G. Marneros, "Effects of chronically increased VEGF-A on the aging heart," The FASEB Journal, vol. 32, no. 3, pp. 1550-1565, 2018.

[33] I. Friehs, R. E. Margossian, A. M. Moran, H. Cao-Danh, M. A. Moses, and P. J. del Nido, "Vascular endothelial growth factor delays onset of failure in pressure-overload hypertrophy through matrix metalloproteinase activation and angiogenesis," Basic Research in Cardiology, vol. 101, no. 3, pp. 204213, 2006.

[34] S. Besse, F. Boucher, G. Linguet et al., "Intramyocardial protein therapy with vascular endothelial growth factor (VEGF-165) induces functional angiogenesis in rat senescent myocardium," Journal of Physiology and Pharmacology, vol. 61, no. 6, pp. 651-661, 2010.

[35] Q. Ge, H. Zhang, J. Hou et al., "VEGF secreted by mesenchymal stem cells mediates the differentiation of endothelial progenitor cells into endothelial cells via paracrine mechanisms," Molecular Medicine Reports, vol. 17, no. 1, pp. 1667-1675, 2018.

[36] S. Y. Ahn, W. S. Park, Y. E. Kim et al., "Vascular endothelial growth factor mediates the therapeutic efficacy of mesenchymal stem cell-derived extracellular vesicles against neonatal hyperoxic lung injury," Experimental \& Molecular Medicine, vol. 50, no. 4, pp. 1-12, 2018.

[37] K. C. Wheeler, M. K. Jena, B. S. Pradhan et al., "VEGF may contribute to macrophage recruitment and M2 polarization in the decidua," PLoS One, vol. 13, no. 1, article e0191040, 2018.

[38] X. H. Xu, J. Xu, L. Xue, H. L. Cao, X. Liu, and Y. J. Chen, "VEGF attenuates development from cardiac hypertrophy to heart failure after aortic stenosis through mitochondrial mediated apoptosis and cardiomyocyte proliferation," Journal of Cardiothoracic Surgery, vol. 6, no. 1, 2011.

[39] Q. Lian, Y. Zhang, X. Liang, F. Gao, and H. F. Tse, "Directed differentiation of human-induced pluripotent stem cells to 
mesenchymal stem cells," Methods in Molecular Biology, vol. 1416, pp. 289-298, 2016.

[40] W. Wagner, P. Horn, M. Castoldi et al., "Replicative senescence of mesenchymal stem cells: a continuous and organized process," PLoS One, vol. 3, no. 5, article e2213, 2008.

[41] J. D. Kretlow, Y. Q. Jin, W. Liu et al., "Donor age and cell passage affects differentiation potential of murine bone marrow-derived stem cells," BMC Cell Biology, vol. 9, no. 1, p. 60, 2008.

[42] S. J. Mutt, T. Karhu, S. Lehtonen et al., "Inhibition of cytokine secretion from adipocytes by 1,25-dihydroxyvitamin D3 via the NF- $\kappa \mathrm{B}$ pathway," The FASEB Journal, vol. 26, no. 11, pp. 4400-4407, 2012.

[43] Y. Zhang, S. Chiu, X. Liang et al., "Rap1-mediated nuclear factor-kappaB (NF-_ $\kappa_{-}$B) activity regulates the paracrine capacity of mesenchymal stem cells in heart repair following infarction," Cell Death Discovery, vol. 1, no. 1, 2015.

[44] X. Liang, Y. Ding, Y. Zhang, H. F. Tse, and Q. Lian, "Paracrine mechanisms of mesenchymal stem cell-based therapy: current status and perspectives," Cell Transplantation, vol. 23, no. 9, pp. 1045-1059, 2014.

[45] C. Zhao and M. Ikeya, "Generation and applications of induced pluripotent stem cell-derived mesenchymal stem cells," Stem Cells International, vol. 2018, Article ID 9601623, 8 pages, 2018. 